University of Wollongong

Research Online

Faculty of Engineering and Information

Faculty of Engineering and Information

Sciences - Papers: Part B

Sciences

2018

Experimental and modeling investigation on separation of methane from coal seam gas (CSG) using hydrate formation

Yiwei Wang

China University of Petroleum, yw367@uowmail.edu.au

Ye Deng

Sinopec Group

Xuqiang Guo

China University of Petroleum, guoxq@cup.edu.cn

Qiang Sun

China University of Petroleum

Aixian Liu

China University of Petroleum

See next page for additional authors

Follow this and additional works at: https://ro.uow.edu.au/eispapers1

Part of the Engineering Commons, and the Science and Technology Studies Commons

Research Online is the open access institutional repository for the University of Wollongong. For further information contact the UOW Library: research-pubs@uow.edu.au 


\title{
Experimental and modeling investigation on separation of methane from coal seam gas (CSG) using hydrate formation
}

\author{
Abstract \\ The effects of temperature, pressure, initial promoter concentration and coal seam gas/liquid ratio on the \\ separation of methane from coal seam gas were experimentally investigated. Low temperature, high \\ pressure and high promoter concentration lead to high separation efficiency and high recovery rate of $\mathrm{CH}$ \\ 4 , but reduce the $\mathrm{CH} 4$ capture selectivity in hydrate. Experimental simulation of a three-stage separation \\ shows that $\mathrm{CH} 4$ can be concentrated from 34.6 to $81.3 \mathrm{~mol} \%$ in the dissociated gas, while its content is \\ only $7.2 \mathrm{~mol} \%$ in the residual gas. An innovative model was established to predict the separation \\ performance. The modeling results reasonably match the experimental data in predicting the effects of \\ different influential factors, with an average relative deviation of $2.83 \%$, the maximum relative deviation \\ $11.2 \%$, and the average relative variance 0.1044 . The modeling results of a three-stage separation process \\ include $81.0 \mathrm{~mol} \%$ of $\mathrm{CH} 4$ in the final dissociated gas and $5.5 \mathrm{~mol} \%$ of $\mathrm{CH} 4$ in the final residual gas. The \\ recovery rate of $\mathrm{CH} 4$ was $90.1 \mathrm{~mol} \%$ and the separation factor was 73.0.

\section{Disciplines} \\ Engineering | Science and Technology Studies

\section{Publication Details} \\ Wang, Y., Deng, Y., Guo, X., Sun, Q., Liu, A., Zhang, G., Yue, G. \& Yang, L. (2018). Experimental and modeling \\ investigation on separation of methane from coal seam gas (CSG) using hydrate formation. Energy, 150 \\ 377-395.
}

\section{Authors}

Yiwei Wang, Ye Deng, Xuqiang Guo, Qiang Sun, Aixian Liu, Guangqing Zhang, Gang Yue, and Lanying Yang 


\section{Experimental and modeling investigation on separation of}

2 methane from coal seam gas (CSG) using hydrate formation

3 Yiwei Wang ${ }^{\mathbf{a}}$, Ye Deng ${ }^{\mathbf{c}}$, Xuqiang Guo $^{\mathbf{b}, *}$, Qiang Sun ${ }^{\mathbf{a}}$, Aixian Liu ${ }^{\mathbf{b}}$, Guangqing Zhang ${ }^{\mathbf{d}}$,

4 Gang Yue, ${ }^{\text {a }}$ Lanying Yang ${ }^{\mathbf{a}}$

5 a State Key Laboratory of Heavy Oil Processing, China University of Petroleum

6 (Beijing), Beijing, 102249, China

7 bState Key Laboratory of Heavy Oil Processing, China University of Petroleum Beijing

8 at Karamay, Karamay, 834000, China

$9 \quad$ SSinopec Yangzi Petrochemical Company LTD. Nanjing,210048, China

10 'School of Mechanical, Materials, Mechatronic and Biomedical Engineering,

11 University of Wollongong, Wollongong, NSW2500, Australia

12 Corresponding author: Xuqiang Guo*, email: guoxq@cup.edu.cn 


\section{Abstract}

The effects of temperature, pressure, initial promoter concentration and coal seam gas/liquid ratio on the separation of methane from coal seam gas were experimentally investigated. Low temperature, high pressure and high promoter concentration lead to high separation efficiency and high recovery rate of $\mathrm{CH}_{4}$, but reduce the $\mathrm{CH}_{4}$ capture selectivity in hydrate. Experimental simulation of a three-stage separation shows that $\mathrm{CH}_{4}$ can be concentrated from 34.6 to $81.3 \mathrm{~mol} \%$ in the dissociated gas, while its content is only $7.2 \mathrm{~mol} \%$ in the residual gas. An innovative model was established to predict the separation performance. The modeling results reasonably match the experimental data in predicting the effects of different influential factors, with an average relative deviation of $2.83 \%$, the maximum relative deviation $11.2 \%$, and the average relative variance 0.1044 . The modeling results of a three-stage separation process include $81.0 \mathrm{~mol}^{\%}$ of $\mathrm{CH}_{4}$ in the final dissociated gas and $5.5 \mathrm{~mol}^{\circ} \mathrm{of} \mathrm{CH}_{4}$ in the final residual gas. The recovery rate of $\mathrm{CH}_{4}$ was $90.1 \mathrm{~mol} \%$ and the separation factor was 73.0.

Key words: Separation; Methane, Coal seam gas; Semi-clathrate hydrate; Modeling; Multistage separation. 


\section{1. Introduction}

Coal seam gas $(\mathrm{CSG})^{[1]}$ is an unconventional source of natural gas extracted from coal beds during the mining process which can be utilized when the $\mathrm{CH}_{4}$ content is above about $80 \mathrm{~mol} \% .^{[2]}$ The concentration of $\mathrm{CH}_{4}$ in the $\mathrm{CSG}$ usually ranges between $10 \mathrm{~mol} \%$ and $70 \mathrm{~mol} \%$, which limits the direct utilization of CSG and makes CSG explosive. ${ }^{[3,4]}$ Since CSG is one of the main causes of mine disasters and is difficult and risky to recycle, ${ }^{[5]}$ it is mostly emitted into the atmosphere after dilution. ${ }^{[6]}$ About $5.54 \times 10^{12} \mathrm{~m}^{3} \mathrm{CSG}$ is emitted into the atmosphere every year, ${ }^{[7]}$ which is a serious environmental problem because $\mathrm{CH}_{4}$ has a global warming effect equivalent to 72 times of $\mathrm{CO}_{2}$ on the weight basis ${ }^{[7,8]}$. In order to utilize this natural gas resource and reduce its greenhouse effect, it is necessary to recover CSG and concentrate the $\mathrm{CH}_{4}$ to about $80 \mathrm{~mol} \% .^{[2,9]}$ Although the processes such as pressure swing adsorption, cryogenic liquefaction and membrane technology are shown to be the effective, ${ }^{[2,10]}$ they are rarely used in industry due to economic and technical reasons. ${ }^{[2]}$

Separation of $\mathrm{CH}_{4}$ from $\mathrm{CSG}$ based on hydrate formation is an innovative technology ${ }^{[9,11-13]}$ which has mild reaction conditions, ${ }^{[14,15]}$ large gas storage capacity, ${ }^{[16,17]}$ simple process ${ }^{[18,19]}$ and low energy consumption, ${ }^{[19,20]}$ and has attracted much attention. Clathrate hydrates are non-stoichiometric inclusion compounds made up of guest molecules encaged within ice-like crystalline structure of water molecules. ${ }^{[21,22]}$ Thermodynamically, different gases need different operating conditions to form hydrates, ${ }^{[23]}$ which is utilized to separate $\mathrm{CH}_{4}$ from CSG. During the hydrate formation, the component possessing milder hydrate formation condition $\left(\mathrm{CH}_{4}\right)$ is enriched and stored in the hydrate phase while the other component $\left.\mathrm{N}_{2}\right)$ is enriched in the gas phase. ${ }^{[9,11-13]}$ The hydrate formation process is not only a process of the recovery and storage 
1 of $\mathrm{CH}_{4}$ but also a process of the $\mathrm{CH}_{4}$ emission reduction.

Additives, as either kinetic or thermodynamic promoters, are added to promote the hydrate formation. ${ }^{[24,25]}$ Thermodynamic promoters participate in hydrate formation thereby alter the hydrate phase equilibrium resulting in more moderate conditions of hydrate formation (lower pressure and higher temperature than forming pure gas hydrates). ${ }^{[26]}$ Commonly used thermodynamic additives for hydrate formation include tetrahydrofuran (THF), ${ }^{[27,}{ }^{28]}$ tetra-n-butyl-ammonium bromide (TBAB) ${ }^{[29,}{ }^{30]}$ and cyclopentane (CP). ${ }^{[31,32]}$ Zhong et al. ${ }^{[12]}$ found that the equilibrium hydrate formation pressure of the model CSG $\left(30 \mathrm{~mol}_{0} \mathrm{CH}_{4}+70 \mathrm{~mol} \% \mathrm{~N}_{2}\right)$ at $273.15 \mathrm{~K}$ can be reduced from 6.9 $\mathrm{MPa}$ to lower than 0.3 $\mathrm{MPa}$ by adding $1 \mathrm{~mol} \% \mathrm{THF}$. Wang et al. ${ }^{[13]}$ reduced the equilibrium hydrate formation pressure of the model $\mathrm{CSG}\left(34.6 \mathrm{~mol} \% \mathrm{CH}_{4}+65.4\right.$ mol $\% \mathrm{~N}_{2}$ ) at $282.15 \mathrm{~K}$ from $16.54 \mathrm{MPa}$ to lower than $1.02 \mathrm{MPa}$ by adding $0.901 \mathrm{~mol} \%$ TBAB. Kinetic promoters (commonly surfactants) do not participate in hydrate formation and have no effect on the phase equilibrium curve, but change the properties of liquid like viscosity and the gas/liquid interfacial tension so as to increase hydrate formation rates. ${ }^{[26]}$ Commonly used kinetic promoters include sodium dodecyl sulfate(SDS), ${ }^{[33,34]}$ sodium dodecyl benzene sulfonate (SDBS) ${ }^{[34]}$ and leucine. ${ }^{[35]}$ The promotion of kinetic promoter on the hydrate formation depends on the concentration of the promoter. Zhou et al. ${ }^{[36]}$ found that the viscosity of SDS solution reaches a peak at $0.05 \mathrm{wt} \%$, and then decreases slowly from $0.05 \mathrm{wt} \%$ to $0.3 \mathrm{wt} \%$ at room temperature. Martinov et al. ${ }^{[37]}$ report the effect of the SDS concentration and surface tension on the mass transfer coefficient for aeration performance in a stirred tank reactor.

Hydrate based separation with additives are widely used in the separation of target components from different gas mixtures such as $\mathrm{CH}_{4}+\mathrm{CO}_{2}{ }^{[24,38,39]}, \mathrm{H}_{2}+\mathrm{CO}_{2}{ }^{[40,41]}$, $\mathrm{CO}_{2}+\mathrm{N}_{2}{ }^{[25,32,42]}$ and model $\mathrm{CSG}\left(\mathrm{CH}_{4}+\mathrm{N}_{2}\right) .{ }^{[9,11-13]}$ In the study of separating $\mathrm{CH}_{4}$ from 
1 CSG using a scale-up bubble column, Cai et al. ${ }^{[9]}$ found the storage of $\mathrm{CH}_{4}$ in hydrate decreased with the increase of gas flow rate. In semi-batch and batch operation, Zhong et al. ${ }^{[11]}$ concentrated $\mathrm{CH}_{4}$ from a $\mathrm{CH}_{4}-\mathrm{N}_{2}$ mixture from 30 to $70 \mathrm{mo} \%$ after two-stage separation. They also found the conversion of water to hydrate in the THF solutionsaturated silica sand bed was better than in a stirred reactor. ${ }^{[12]}$ Wang et al. [13] concentrated $\mathrm{CH}_{4}$ from 34.6 to $79.9 \mathrm{~mol} \%$ after four-step separation of $\mathrm{CH}_{4}+\mathrm{N}_{2}$ mixture in a continuous hydrate formation process.

TBAB is a very effective thermodynamic hydrate formation promoter for the separation of $\mathrm{CH}_{4}$ from CSG. Besides, it has a number of advantages, e.g. environmentfriendly, high solubility in water, low vitality and good fluidity. ${ }^{[43]}$ In addition, TBAB hydrate are less likely to cause apparatus blockage due to very fine TBAB hydrate crystal particles, ranging between $10^{-4}$ and $10^{-5} \mathrm{~m}$, which are hardly conglomerated with one another. ${ }^{[43]}$ So TBAB was chosen as the promoter in this study. This study aims to investigate the effects of various operating parameters on the hydrate based separation. Table 1 summarizes the experimental conditions employed in the current study in comparison with those in above references.

To better understand the hydrate based CSG separation, the effects of different factors on the separation efficiency and gas storage need to be quantitatively evaluated. In addition, for the application of the experimental data in industrial design, a mathematical model is needed to predict the performance of the hydrate based separation and gas storage capacity of hydrate under different operating conditions. Though much research has been done into the modelling of hydrate, it mainly focuses on formation mechanism, ${ }^{[44,45]}$ cold storage ${ }^{[46]}$ and phase equilibria. ${ }^{[47-49]}$ Fukumoto et al. ${ }^{[50]}$ proposed a model to predict the separation of $\mathrm{CO}_{2}$ and $\mathrm{H}_{2}$ at the hydrate melting point. Tumba et al. ${ }^{[51]}$ proposed a model to predict the separation of three binary-gas 


\section{Experimental Section} study.

\subsection{Materials and apparatus}

mixtures of close-boiling point compounds $\left(\mathrm{C}_{2} \mathrm{H}_{6}+\mathrm{C}_{2} \mathrm{H}_{4}, \mathrm{C}_{2} \mathrm{H}_{2}+\mathrm{C}_{3} \mathrm{H}_{6}\right.$, and $\mathrm{C}_{2} \mathrm{H}_{2}+$ $\mathrm{C}_{3} \mathrm{H}_{8}$ ) with pure water. A mathematical model to predict the effects of different factors on the separation efficiency and the gas storage has not been available in previous works. The accuracy of the models in predicting separation performance needs to be improved, and the ranges of the operating conditions the models can be applied need to be widened. For these reasons, this work proposes new models for single stage and multistage separation to quantitatively evaluate the effects of different factors on the hydrate based separation and the gas storage. The effectiveness of the models in predicting the performance of the hydrate based separation is verified by the experimental data of this

(1)

The actual $\mathrm{CSG}$ gas mainly consists of $\mathrm{CH}_{4}, \mathrm{~N}_{2}$ and $\mathrm{O}_{2} .{ }^{[2,52]}$ The concentration of the $\mathrm{O}_{2}$ in $\mathrm{CSG}$ is far less than those of $\mathrm{CH}_{4}$ and $\mathrm{N}_{2}$, and the equilibrium hydrate formation conditions between $\mathrm{O}_{2}$ and $\mathrm{N}_{2}$ hydrate are close. ${ }^{[53,11,13]}$ Hence, CSG was modeled by $\mathrm{CH}_{4}-\mathrm{N}_{2}$ mixtures in this study. ${ }^{[9,11-13]}$ The gas mixtures were supplied by AP Beifen Gas Industry Co. in cylinders, containing 13.3, 23.7, 34.6, 50.9 and 65.9 mol\% of $\mathrm{CH}_{4}$, respectively. TBAB of $99.99 \mathrm{wt} \%$ purity was supplied by Shanghai Sinopharm Chemical Reagent. The TBAB solutions were obtained by mixing TBAB and deionized water which were weighed by an electronic balance with the precision of $\pm 0.1 \mathrm{mg}$. The concentrations of TBAB in aqueous solutions include 10.0, 12.0, 14.0 and $16.0 \mathrm{wt} \%$, corresponding to $0.617,0.756,0.901$ and $1.052 \mathrm{~mol} \%$ correspondingly. The 
1 compositions of the dissociated gas and residual gas were determined by a gas

2 chromatograph (Agilent 7890).

\section{$\begin{array}{llll}3 & 2.2 & \text { Viscosity and interfacial tension }\end{array}$}

\section{4 measurements}

The dynamic viscosity of TBAB solutions was measured using a KV-4 viscometer (GB/T265-88). The experimental apparatus for measuring the interfacial tension between TBAB solution and the model CSG containing $34.6 \mathrm{~mol}^{2} \mathrm{CH}_{4}$ are reported in previous papers published by this laboratory. ${ }^{[54,55]}$ The experimental procedures for measuring the interfacial tension are reported in detail in previous papers published by this laboratory. ${ }^{[54,55]}$

\subsection{Hydrate based separation}

\subsubsection{Apparatus}

The schematic of the experimental apparatus is shown in Fig. 1. It consists of a manual pump, an air bath, a crystallizer and a temperature and pressure measuring system. The crystallizer is a volume variable cell with a maximum volume of $465 \mathrm{ml}$, in which a stirrer is fixed to the bottom to continually stir the solution. The manual pump with scale division lines of $\pm 0.05 \mathrm{ml}$ uncertainty is used to control the volume of the crystallizer. The air bath can control the temperature of the crystallizer between 243.15 K and $323.15 \mathrm{~K}$. The temperature inside the crystallizer is measured by a platinum resistance thermometer with an uncertainty of $\pm 0.05 \mathrm{~K}$. The pressure in the 
1 crystallizer is measured by a pressure sensor with an uncertainty of $\pm 0.005 \mathrm{MPa}$.

\section{$2 \quad$ 2.3.2 Operation procedure}

Prior to an experiment, the crystallizer was washed with deionizer water and dried. The volume of the crystallizer was then adjusted using the manual pump based on Eq. (1).

$$
\mathrm{V}_{\mathrm{cr}, 0}=\mathrm{V}_{\mathrm{sol}}+\left(\mathrm{V}_{\mathrm{sol}} \cdot \mathrm{CL}\right) \cdot \frac{\mathrm{P}_{\mathrm{stp}}}{\mathrm{P}} \cdot \frac{\mathrm{T}}{\mathrm{T}_{\mathrm{stp}}} \cdot \frac{\mathrm{Z}_{\mathrm{CSG}}}{\mathrm{Z}_{\mathrm{CSG}, \mathrm{stp}}}
$$

where $\mathrm{V}_{\mathbf{c r}, \mathbf{0}}$ is the volume of the crystallizer and $\mathrm{V}_{\text {sol }}$ is the volume of the TBAB solution in the crystallizer at the beginning of an experiment. $Z_{\text {CSG }}$ and $Z_{\text {CSG,stp are the }}$ compressibility factors of the model CSG under experimental condition and under 273.15K, $101325 \mathrm{~Pa}$, respectively, calculated by Patel-Teja EOS. ${ }^{[56]} \mathrm{P}$ and $\mathrm{T}$ denote the experimental pressure and temperature. $\mathrm{T}_{\text {stp }}$ is $273.15 \mathrm{~K}$ and $\mathrm{P}_{\text {stp }}$ is $101325 \mathrm{~Pa}$. CL (CSG/liquid ratio) is the volumetric ratio of model CSG (under $273.15 \mathrm{~K}, 101325 \mathrm{~Pa}$ ) to the TBAB solution at the beginning of an experiment.

The temperature of the air bath was set at the desired value. A measuring cylinder containing $\mathrm{TBAB}$ solution was put into the air bath to keep the TBAB solution at the desired temperature. The crystallizer was evacuated and then filled with the model CSG. When the crystallizer reached the experimental temperature, it was evacuated and a desired amount of TBAB solution was injected from the measuring cylinder into the crystallizer. The crystallizer and tubing were purged three times using the model CSG to completely remove air from the system. When the temperature of the crystallizer and TBAB solution became constant at the experimental temperature, the desired amount of model CSG was injected into the crystallizer. Once the pressure in the crystallizer reached the desired value, the valves of the crystallizer were closed to isolate the crystallizer from the gas cylinder. The stirrer was started at a constant speed of $500 \mathrm{rpm}$. 
1 This moment was noted as the start of a hydrate based gas separation experiment. Along

2 with the consumption of CSG by hydrate formation, the pressure in the crystallizer was

3 maintained constant by the manual pump. When the volume of the crystallizer remained

4 constant for at least $2 \mathrm{~h}$, it was considered that the separation reaction reached

5 equilibrium and then ended. The stirrer was stopped, and the residual gas in the crystallizer was sampled at constant pressure and the composition analyzed. Then, the vent valve was opened, and the residual gas was quickly purged. Subsequently, the vale was closed, and the crystallizer was warmed to $298.15 \mathrm{~K}$ to allow the hydrate to dissociate completely. The composition of the dissociated gas was then analyzed. The sampling method was adopted from elsewhere. ${ }^{[39,57-60]}$ The experiment under each operating condition was repeated for 3 times.. The simplified schematic of the experimental procedure is provided in Fig. 2.

\subsection{Treatment of experimental data}

The gas uptake in hydrate $\left(\mathrm{N}_{\mathbf{d}}, \mathrm{mol}\right)$ when the separation reached equilibrium ( teq $)$ is calculated by Eq. (2).

$$
\mathrm{N}_{\mathrm{d}}=\frac{\mathrm{P} \cdot V_{c r, 0}}{\mathrm{Z}_{\mathrm{CSG}} \cdot R^{\prime} \cdot T}-\frac{\mathrm{P} \cdot V_{c r, t_{e q}}}{\mathrm{Z}_{\mathrm{r}} \cdot R \cdot T}
$$

where $V_{\text {cr,teq }}$ is the volume of the crystallizer when the separation reached equilibrium (teq), $Z_{r}$ the compressibility factor of the gas mixture in the crystallizer when the separation reached equilibrium (the residual gas) under experimental condition. $\mathrm{R}$ is gas constant. $\left(8.3145 \mathrm{~J} \cdot \mathrm{mol}^{-1} \cdot \mathrm{K}^{-1}\right)$

The uncertainties in the volume of the crystallizer $( \pm 0.05 \mathrm{ml})$, temperature $( \pm$ $0.05 \mathrm{~K})$ and pressure $( \pm 0.005 \mathrm{MPa})$ are considered while calculating the uncertainty in

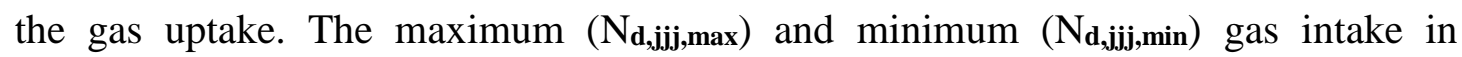


1 individual experiments due to the uncertainties of measured parameters are calculated

2 by Eqs. (3a) and (3b). The mean gas intake $\left(\overline{\mathrm{N}_{\mathrm{d}}}\right)$ and the uncertainty caused by

3 uncertainties of measurement in each experiment $\left(\mathrm{N}_{\mathrm{d}, \mathrm{u}, \mathrm{jjj}}\right)$ and its uncertainty for three

4 repeated experiments $\left(\mathrm{N}_{\mathrm{d}, \mathrm{u}}\right)$ are calculated by Eqs. (3c) and (3e):

$5 \quad \mathrm{~N}_{\mathrm{d}, \mathrm{jj}, \text { max }}=\frac{\mathrm{P}+0.005 \mathrm{MPa}}{\mathrm{R} \cdot(\mathrm{T}-0.05 \mathrm{~K})} \cdot\left(\frac{\mathrm{V}_{\mathrm{cr}, 0}+0.05 \mathrm{ml}}{\mathrm{Z}_{\mathrm{CSG}}}-\frac{\mathrm{V}_{\mathrm{cr}, \mathrm{t}_{\mathrm{eq}}}-0.05 \mathrm{ml}}{\mathrm{Z}_{\mathrm{r}, \mathrm{jj}}}\right)$

$6 \quad \mathrm{~N}_{\mathrm{d}, \mathrm{jjj}, \mathrm{min}}=\frac{\mathrm{P}-0.005 \mathrm{MPa}}{\mathrm{R} \cdot(\mathrm{T}+0.05 \mathrm{~K})} \cdot\left(\frac{\mathrm{V}_{\mathrm{cr}, 0}-0.05 \mathrm{ml}}{\mathrm{Z}_{\mathrm{CSG}}}-\frac{\mathrm{V}_{\mathrm{cr}, \mathrm{t}_{\mathrm{eq}}}+0.05 \mathrm{ml}}{\mathrm{Z}_{\mathrm{r}, \mathrm{jj}}}\right)$

$7 \quad \overline{N_{d}}=\Sigma N_{d, j j j} / 3$

$$
\begin{aligned}
& \mathrm{N}_{\mathrm{d}, \mathrm{u}, \mathrm{jjj}}=\max \left\{\left|\mathrm{N}_{\mathrm{d}, \mathrm{jjj}, \max }-\mathrm{N}_{\mathrm{d}, \mathrm{jjj}}\right|,\left|\mathrm{N}_{\mathrm{d}, \mathrm{jjj}}-\mathrm{N}_{\mathrm{d}, \mathrm{jjj}, \min }\right|\right\} \\
& \mathrm{N}_{\mathrm{d}, \mathrm{u}}=\max \left\{\left|\mathrm{N}_{\mathrm{d}, \mathrm{jjj}, \max }-\overline{\mathrm{N}_{\mathrm{d}}}\right|,\left|\overline{\mathrm{N}_{\mathrm{d}}}-\mathrm{N}_{\mathrm{d}, \mathrm{jj}, \min }\right|\right\}
\end{aligned}
$$

where $\mathrm{jjj}$ is the sequence number for the three repeated experiments. The mean gas storage capacity of hydrate slurry ( $\overline{\mathrm{GSCHS}}, \mathrm{NL} / \mathrm{L})$ is calculated by Eq. (4).

$$
\overline{\mathrm{GSCHS}}=\left(\sum \frac{\mathrm{Z}_{\mathrm{d}, \mathrm{stp}, \mathrm{jj} \cdot \mathrm{N}_{\mathrm{d}, \mathrm{jjj}} \cdot R \cdot \mathrm{T}_{\mathrm{stp}}}}{\mathrm{P}_{\mathrm{stp}} \cdot \mathrm{V}_{\mathrm{sol}}}\right) / 3
$$

The mean separation factor $(\overline{\mathrm{SF}})$ and the mean recovery fraction $(\overline{\mathrm{RF}})$ of the target gas component are calculated as follows:

$$
\begin{aligned}
& \overline{\mathrm{SF}}=\left(\sum \frac{\mathrm{x}_{\mathrm{CH}_{4}, \mathrm{jjj}} \cdot \mathrm{y}_{\mathrm{N}_{2}, \mathrm{jj}}}{\mathrm{x}_{\mathrm{N}_{2}, \mathrm{jjj}} \mathrm{y}_{\mathrm{CH}_{4}, \mathrm{jj}}}\right) / 3 \\
& \overline{\mathrm{RF}}=\left(\sum \frac{\mathrm{N}_{\mathrm{d}, \mathrm{jj}} \cdot \mathrm{x}_{\mathrm{CH}_{4}, \mathrm{jj}}}{\mathrm{N}_{\mathrm{CSG}} \cdot \mathrm{y}_{\mathrm{CH}_{4}, \mathrm{CSG}}}\right) / 3
\end{aligned}
$$

where $\mathrm{XCH}_{4}$ and $\mathrm{x}_{\mathbf{N} 2}$ are the concentrations of $\mathrm{CH}_{4}$ and $\mathrm{N}_{2}$ in the dissociated gas; $\mathrm{yCH}_{4}$ and $\mathrm{y}_{2}$ are the concentrations of $\mathrm{CH}_{4}$ and $\mathrm{N}_{2}$ in the residual gas; $\mathrm{N}_{\mathbf{C S G}}$ is the molar amount of model CSG injected into the crystallizer; yCH4,CSG is the concentration of $\mathrm{CH}_{4}$ in model CSG. The uncertainties of GSCHS, SF and RF caused by the uncertainties of measurement in each experiment and the repeat experiments are calculated by Eqs. (7a) to (7e): 


$$
\mathrm{GSCHS}_{u, j j j}=\max \left\{\left|\frac{\mathrm{z}_{\mathrm{d}, \mathrm{stp}, \mathrm{jjj}} \cdot \mathrm{N}_{\mathrm{d}, \mathrm{u}, \mathrm{jjj}} \cdot R \cdot \mathrm{T}_{\mathrm{stp}}}{\mathrm{P}_{\mathrm{stp}} \cdot \mathrm{V}_{\mathrm{sol}}}\right|\right\}
$$

$2 \mathrm{GSCHS}_{u}=\max \left\{\left|\frac{\mathrm{Z}_{\mathrm{d}, \mathrm{stp}, \mathrm{jjj}} \cdot \mathrm{N}_{\mathrm{d}, \mathrm{jj}, \max } \cdot R \cdot \mathrm{T}_{\mathrm{stp}}}{\mathrm{P}_{\mathrm{stp}} \cdot \mathrm{V}_{\mathrm{sol}}}-\overline{\mathrm{GSCHS}}\right|,\left|\overline{\mathrm{GSCHS}}-\frac{\mathrm{Z}_{\mathrm{d}, \mathrm{stp}, \mathrm{jj}} \cdot \mathrm{N}_{\mathrm{d}, \mathrm{jj}, \min } \cdot R \cdot \mathrm{T}_{\mathrm{stp}}}{\mathrm{P}_{\mathrm{stp}} \cdot \mathrm{V}_{\mathrm{sol}}}\right|\right\}$

$3 \quad \mathrm{RF}_{u, \mathrm{jjj}}=\max \left\{\left|\frac{\mathrm{N}_{\mathrm{d}, \mathrm{u}, \mathrm{jjj}} \cdot \mathrm{x}_{\mathrm{CH}_{4}, \mathrm{jjj}}}{\mathrm{N}_{C S G} \cdot \mathrm{y}_{\mathrm{CH}_{4}, \mathrm{CSG}}}\right|\right\}$

$4 \quad \mathrm{RF}_{u}=\max \left\{\left|\frac{\mathrm{N}_{\mathrm{d}, \mathrm{jj}, \mathrm{max}} \cdot \mathrm{x}_{\mathrm{CH}_{4}, \mathrm{jj}}}{\mathrm{N}_{C S G} \cdot \mathrm{y}_{\mathrm{CH}_{4}, \mathrm{CSG}}}-\overline{\mathrm{RF}}\right|,\left|\overline{\mathrm{RF}}-\frac{\mathrm{N}_{\mathrm{d}, \mathrm{jj}, \mathrm{min}} \cdot \mathrm{x}_{\mathrm{CH}_{4}, \mathrm{jj}}}{\mathrm{N}_{C S G} \cdot \mathrm{y}_{\mathrm{CH}_{4}, \mathrm{CSG}}}\right|\right\}$

$5 \quad \mathrm{SF}_{u}=\max \left\{\left|\frac{\mathrm{x}_{\mathrm{CH}_{4}, \mathrm{jj}} \cdot \mathrm{y}_{\mathrm{N}_{2}, \mathrm{jj}}}{\mathrm{x}_{\mathrm{N}_{2, j}, \mathrm{jj}} \cdot \mathrm{y}_{\mathrm{CH}_{4}, \mathrm{jj}}}-\overline{\mathrm{SF}}\right|\right\}$

\section{3. Modeling}

\section{3.1 TBAB semi-clathrate hydrate formation}

As discussed in introduction, TBAB participates in the formation of TBAB semiclathrate hydrate (not gas hydrate), resulting in more moderate condition of hydrate formation. Meanwhile, TBAB is a salt which weakens the hydrogen bonds between water molecules, so TBAB can also inhibit hydrate formation. ${ }^{[61,62]}$ Therefore, TBAB has two competing effects on hydrate formation, and an inflection temperature is presented in the hydrate phase equilibrium diagram of the gas mixture $+\mathrm{TBAB}$ aqueous systems. ${ }^{[47,63]}$ When temperature is below the inflection temperature, TBAB works as a thermodynamic promoter, and the equilibrium hydrate formation pressure is lower than that in pure water systems; when temperature is above the inflection temperature, TBAB works as a thermodynamic inhibitor, and the equilibrium hydrate formation pressure is higher than that in pure water system. ${ }^{[47,63]}$

Previous work ${ }^{[13]}$ shows that in the temperature range of this study, a CSG consisting of $34.6 \mathrm{~mol} \% \mathrm{CH}_{4}+65.4 \mathrm{~mol} \% \mathrm{~N}_{2}$ has much lower equilibrium hydrate 
1 formation pressure in the TBAB aqueous system than in pure water system. The experimental temperature is well below the inflection temperature, and TBAB works as a thermodynamic promoter. The operating pressure in this work is higher than the equilibrium hydrate formation pressure in the TBAB aqueous system but much lower than that in pure water system. The hydrate formed under the operating conditions in this work is mainly TBAB semi-clathrate hydrate rather than gas hydrate consisting of only gas and water molecules.

In this work, the two-step hydrate formation mechanism proposed by Chen and $\mathrm{Guo}^{[44]}$ is used to simulate the process of the formation of TBAB semi-clathrate hydrate: First step: TBAB and water molecules form basic semi-clathrate hydrate. The concept of basic hydrate has been discussed in detail in a previous article. ${ }^{[45]}$ Following Long and Sloan, ${ }^{[64]}$ each TBAB molecule dissolved in water is assumed forming a labile cluster with the water molecules surrounding it. Then the clusters associate with one another to form the so-called basic hydrates. The formation of basic semi-clathrate hydrate is illustrated by the following equation:

$$
\mathrm{H}_{2} \mathrm{O}+\lambda_{2} \mathrm{TBAB} \rightarrow \mathrm{TBAB}_{\lambda_{2}} \cdot \mathrm{H}_{2} \mathrm{O}
$$

$\lambda_{2}$ is the ratio of TBAB-to-water molecule numbers in a basic hydrate unit. Types A and B hydrate have TBAB $\cdot 26 \mathrm{H}_{2} \mathrm{O}$ and $\mathrm{TBAB} \cdot 38 \mathrm{H}_{2} \mathrm{O}$ unit cells, respectively. ${ }^{[65]}$ Each TBAB semi-clathrate hydrate cell unit is composed of $2 \mathrm{TBA}^{+}$and $2 \mathrm{Br}^{-}$along with 52 water molecules for type A and 76 water molecules for type B. ${ }^{[65]} \mathrm{TBA}^{+}$is trapped into a basic cavity formed by two large tetrakaidecahedra and two pentakaidecahedra, respectively. It should be noted that four similar large cavities are involved, $\lambda_{2}$ is $2 / 52$ for type A and 2/76 for type B. During this step, the linked cavities (the small cavities formed by 12 pentagons) form automatically. ${ }^{[44]}$

Second step: small molecules like $\mathrm{N}_{2}$ and $\mathrm{CH}_{4}$ are captured into empty linked 
1 cavities of basic semi-clathrate hydrate. The occupation of linked cavities by small gas

2 molecules reduces the chemical potential of the basic hydrate, making the structure of

3 the semi-clathrate hydrate more stable and leading to the formation of final semi-

4 clathrate hydrate structure:

$5 \theta_{\mathrm{CH}_{4}} \lambda_{1} \mathrm{CH}_{4}+\theta_{\mathrm{N}_{2}} \lambda_{1} \mathrm{~N}_{2}+\mathrm{TBAB}_{\lambda_{2}} \cdot \mathrm{H}_{2} \mathrm{O} \rightarrow\left(\mathrm{CH}_{4}\right)_{\theta_{\mathrm{CH}_{4}} \lambda_{1}}\left(\mathrm{~N}_{2}\right)_{\theta_{\mathrm{N}_{2}} \lambda_{1}} \mathrm{TBAB}_{\lambda_{2}} \cdot \mathrm{H}_{2} \mathrm{O}$ TBAB semi-clathrate hydrate unit. $\lambda_{1}$ is $3 / 52$ for type $A$ and $3 / 76$ for type $B .{ }^{[66]} \theta_{\mathbf{N} 2}$ and equilibria in the system: the basic hydrate formation in the first step and the physical adsorption of the gas molecules in the linked cavities during the second step. For the chemical equilibrium of Eq. $(8):[44,45,67]]$

$$
\begin{aligned}
& \mu_{\mathrm{B}}^{0}-\mu_{\mathrm{H}_{2} \mathrm{O}}-\lambda_{2} \mu_{\mathrm{TBAB}}^{0}=\lambda_{2} \text { RTInf }_{\mathrm{TBAB}}^{0} \\
& \mu_{\mathrm{TBAB}}=\mu_{\mathrm{TBAB}}^{0}+\mathrm{RT}^{0} \operatorname{lnf}_{\mathrm{TB} A B}
\end{aligned}
$$

where $\mathrm{f}_{\mathrm{TBAB}}^{0}$ is the fugacity of the TBAB in the basic TBAB semi-clathrate hydrate; $\mu_{\mathrm{B}}^{0}$ is the chemical potential of the basic TBAB semi-clathrate hydrate; $\mu_{\mathbf{H} 2 \mathbf{O}}$ and $\mu$ TBAB are the chemical potential of water and TBAB in the aqueous solution, respectively; $\mu_{\mathrm{TBAB}}^{0}$ is the chemical potential of the TBAB under standard condition $(273.15 \mathrm{~K}$, $101325 \mathrm{~Pa}$ ). fтвAB is the fugacity of the TBAB in the liquid phase under the experimental condition. The adsorption of $\mathrm{CH}_{4}$ and $\mathrm{N}_{2}$ molecules in the linked cavities reduces the chemical potential of the basic hydrate. At the adsorption equilibrium (Eq. 9), the chemical potential of the final hydrate $\mu_{\mathrm{B}}$ is: ${ }^{[44]}$

$$
\mu_{\mathrm{B}}=\mu_{\mathrm{B}}^{0}+\lambda_{1} \mathrm{RT} \ln \left(1-\theta_{\mathrm{CH}_{4}}-\theta_{\mathrm{N}_{2}}\right)
$$

Therefore, the change of chemical potential during the formation of TBAB semiclathrate hydrate is the difference between the value of the final state and the initial 
state:

2

3

$$
\begin{aligned}
& \mu_{\text {initial }}=\mu_{\mathrm{H}_{2} \mathrm{O}}+\lambda_{2} \mu_{\mathrm{TBAB}} \\
& \Delta \mu=\mu_{\mathrm{B}}-\mu_{\text {initial }}
\end{aligned}
$$

$$
\text { Combining Eqs. (10) - (14), Eq. (15) is obtained: }
$$

$$
\Delta \mu=\mathrm{RT}\left[\lambda_{2} \ln \frac{\mathrm{f}_{\mathrm{TBAB}}^{\mathrm{0}}}{\mathrm{f}_{\mathrm{TBAB}}}+\lambda_{1} \ln \left(1-\theta_{\mathrm{CH}_{4}}-\theta_{\mathrm{N}_{2}}\right)\right]
$$

Based on the Langmuir adsorption theory, $\theta_{\mathbf{C H} 4}$ and $\theta_{\mathrm{N} 2}$ can be calculated as follows: ${ }^{[68,69]}$

$$
\begin{gathered}
\theta_{\mathrm{CH}_{4}}=\frac{\mathrm{f}_{\mathrm{CH}_{4}} \mathrm{C}_{\mathrm{CH}_{4}}}{1+\mathrm{f}_{\mathrm{CH}_{4}} \mathrm{C}_{\mathrm{CH}_{4}}+\mathrm{f}_{\mathrm{N}_{2}} \mathrm{C}_{\mathrm{N}_{2}}} \\
\theta_{\mathrm{N}_{2}}=\frac{\mathrm{f}_{\mathrm{N}_{2}} \mathrm{C}_{\mathrm{N}_{2}}}{1+\mathrm{f}_{\mathrm{CH}_{4}} \mathrm{C}_{\mathrm{CH}_{4}}+\mathrm{f}_{\mathrm{N}_{2}} \mathrm{C}_{\mathrm{N}_{2}}}
\end{gathered}
$$

where $f_{\mathrm{N} 2}$ and $\mathrm{f}_{\mathrm{CH}} 4$ denote the fugacity of $\mathrm{N}_{2}$ and $\mathrm{CH}_{4}$ in the gas phase which is calculated by Patel-Teja EOS. ${ }^{[56]} \mathrm{CN}_{\mathbf{N} 2}$ and $\mathrm{C}_{\mathbf{C H} 4}$ are the Langmuir constants of the adsorption of $\mathrm{N}_{2}$ and $\mathrm{CH}_{4}$ in $\mathrm{TBAB}$ semi-clathrate hydrate and correlated as an Antoine type equation:

$$
\mathrm{C}=\mathrm{X}^{\prime} \exp \left(\frac{\mathrm{Y}^{\prime}}{\mathrm{T}-\mathrm{Z}^{\prime}}\right)
$$

The Antoine parameters for $\mathrm{N}_{2}$ and $\mathrm{CH}_{4}$ are fitted based on the experimental data in this study by trial-and-error method. The fitting process is shown in supplementary materials. The obtained values of $\mathrm{X}^{\prime}, \mathrm{Y}^{`}$ and $\mathrm{Z}^{\prime}$ are listed in Table 2:

$$
\mathrm{f}_{\text {TВАВ }}^{0} \text { can be calculated as follows: }{ }^{[47,48]}
$$

$$
\mathrm{f}_{\mathrm{TBAB}}^{0}=\mathrm{f}_{\mathrm{T}}^{0}(\mathrm{~T}) \exp \left(\frac{\beta \mathrm{P}}{\mathrm{T}}\right) \alpha_{\mathrm{H}_{2} \mathrm{O}}^{-1 / \lambda_{2}}
$$

$$
\alpha_{\mathrm{H}_{2} \mathrm{O}}=\exp \left(-0.03321 \mathrm{w}_{\mathrm{TBAB}}^{2}-0.09463 \mathrm{w}_{\mathrm{TBAB}}-2.5874 \times 10^{-4}\right)
$$

$$
\mathrm{A}_{\mathrm{N}_{2}}=-400 \mathrm{w}_{\mathrm{TBAB}}+50
$$


1 where $\mathrm{fT}^{0}(\mathrm{~T})$ is a function of temperature. The Antoine constants $\mathrm{A}^{\prime}, \mathrm{B}^{\prime}$ and $\mathrm{C}^{\prime}$ for

$2 \mathrm{TBAB}$ are shown in Table 3. ACH4 and $\mathrm{A}_{\mathbf{N} 2}$ are the corrected coefficients between small

3 gas molecules $\left(\mathrm{N}_{2}\right.$ and $\left.\mathrm{CH}_{4}\right)$ and $\mathrm{TBAB}$ which can be expressed as a function of TBAB

4 concentration. $\beta$ is a parameter which depends on the structure of the hydrate; it is 2.8

$5 \mathrm{~K} / \mathrm{bar}$ for type A and $3.5 \mathrm{~K} / \mathrm{bar}$ for type B. $\alpha \mathbf{H 2 O}$ is the activity of water in the TBAB

6 solution. WTBAB is the mass fraction of TBAB in solution.

$\mathrm{f}_{\text {TBAB }}$ can be calculated as follows: ${ }^{[48,69-74]}$

where $\mathrm{x}_{\mathbf{A} \mathbf{A B}}, \mathrm{v}_{\mathrm{TBAB}}^{\mathrm{L}}$, and $\gamma_{\mathbf{T B A B}}$ are the molar fraction, molar volume and activity coefficient of TBAB in solution, respectively; $\mathrm{P}_{\mathrm{TBAB}}^{\mathrm{sat}}$ is the saturated vapor pressure of TBAB; $M_{\text {sol }}$ and $\rho_{\text {sol }}$ are the molecular weight and density of TBAB solution; $\rho_{\text {нго }}$ is the density of water; $\mathrm{q}_{\mathrm{i}}, \mathrm{g}_{\mathrm{i}}$, and $\mathrm{si}_{\mathrm{i}}$ are empirical constants, which are presented in Table 4. In Eq. (26a), $\rho_{\text {sol }}$ is in $\mathrm{g} / \mathrm{cm}^{3}$.

\subsection{CSG separation via hydrate forming}

During a CSG separation process, the hydrate formation rate and gas composition continuously change due to the changes in the hydrate formation driving force and the preferential $\mathrm{CH}_{4}$ capture by the hydrate slurry. In this study, the CSG separation process 
1 was simulated by the differential method. The separation duration was divided into

2 thousands of time units $(\Delta \mathrm{t})$. During each time unit, the process was approximated as a

3 steady state, i.e. the gas composition and amount, the concentration of TBAB in the

4 liquid phase, and the hydrate slurry composition are assumed to remain constant. Thus,

5 the driving force for hydrate formation and preferential $\mathrm{CH}_{4}$ capture by hydrate slurry

6 remains constant. The conceptual model of the hydrate-based gas separation is shown

7 in Fig. 4.

8 At the beginning of an experiment $(\mathrm{t}=0)$, no hydrate is present; there are only

9 model CSG and fresh TBAB solution in the crystallizer. The initial conditions are:

$$
\begin{aligned}
& \mathrm{N}_{\mathrm{CSG}}=\frac{\mathrm{P}_{\text {stp }} \cdot \mathrm{CL} \cdot \mathrm{V}_{\text {sol }}}{R \cdot \mathrm{Z}_{\mathrm{CSG}, \mathrm{stp}} \cdot \mathrm{T}_{\mathrm{stp}}} \\
& \mathrm{y}_{\mathrm{CH}_{4}, 0}=\mathrm{y}_{\mathrm{CH}_{4}, \mathrm{CSG}} \\
& \mathrm{y}_{\mathrm{N}_{2}, 0}=\mathrm{y}_{\mathrm{N}_{2}, \mathrm{CSG}} \\
& \mathrm{Ng}_{\mathrm{CH}_{4}, 0}=\mathrm{N}_{\mathrm{CSG}} \cdot \mathrm{y}_{\mathrm{CH}_{4}, 0} \\
& \mathrm{Ng}_{\mathrm{N}_{2}, 0}=\mathrm{N}_{\mathrm{CSG}} \cdot \mathrm{y}_{\mathrm{N}_{2}, 0} \\
& \mathrm{Hg}_{\mathrm{CH} H_{4}, 0}=\mathrm{Hg}_{\mathrm{N}_{2}, 0}=0 \\
& \mathrm{~N}_{\mathrm{TBAB}, 0}=\frac{\mathrm{w}_{\mathrm{TBAB}, 0} \cdot \mathrm{m}_{\text {sol }}}{\mathrm{M}_{\mathrm{TBAB}}} \\
& \mathrm{N}_{\mathrm{H}_{2} \mathrm{O}, 0}=\frac{\left(1-\mathrm{w}_{\mathrm{TBAB}, 0} \cdot\right) \cdot \mathrm{m}_{\text {sol }}}{\mathrm{M}_{\mathrm{H}_{2} \mathrm{O}}}
\end{aligned}
$$

where $\mathrm{Ng}_{\mathrm{CH}} 4$ and $\mathrm{Ng}_{\mathbf{N} 2}$ are the moles of the $\mathrm{CH}_{4}$ and the $\mathrm{N}_{2}$ in the gas phase in the crystallizer. $\mathrm{Hg}_{\mathrm{CH} 4}$ and $\mathrm{Hg}_{\mathbf{N} 2}$ are the moles of the $\mathrm{CH}_{4}$ and the $\mathrm{N}_{2}$ in the hydrate slurry in the crystallizer. $\mathrm{N}_{\mathbf{T}} \mathrm{Ba}$ and $\mathrm{N}_{\mathbf{H} 20}$ are the moles of the TBAB and the water in the solution in the crystallizer. WтвAB is the mass fraction of the TBAB in the fresh TBAB solution. Subscript "0" denotes the initial values of corresponding variables. yCH4,CSG and yN2,CSG are the concentrations of the $\mathrm{CH}_{4}$ and the $\mathrm{N}_{2}$ in the model CSG. MTBAB and 
1 MH2O are the molecular weight of TBAB and water. $m_{\text {sol }}$ is the mass of the fresh TBAB

solution injected into the crystallizer.

The molar fraction of TBAB in the TBAB semi-clathrate hydrate is between 2.56 $\mathrm{mol} \%$ and $4 \mathrm{~mol} \%,{ }^{[57]}$ which is much higher than that of TBAB in the solution. Along with the formation of the TBAB semi-clathrate hydrate, the concentration of TBAB in the liquid phase decreases. Because of preferential $\mathrm{CH}_{4}$ capture by the hydrate slurry $\left(\theta_{\mathbf{C H} 4} / \theta_{\mathrm{N} 2}>y_{\mathbf{C H} 4} / \mathrm{y}_{\mathbf{N} 2}\right)$, the concentration of $\mathrm{CH}_{4}$ in the residual gas also decreases. These changes reduce the driving force of the hydrate formation $(-\Delta \mu)$, so the hydrate formation rate decreases along with the progress of the separation. Finally, as the driving force approaches zero $(-\Delta \mu \approx 0)$, the amount of the hydrates stop increasing, that is, the separation reaches an equilibrium state.

The gas capture rate $r\left(\mathrm{~mol} \cdot \Delta \mathrm{t}^{-1}\right)$ is a function of the hydrate formation driving force $(-\Delta \mu)$ which is determined by TBAB concentration, pressure, temperature and gas composition. Based on the GSCHS and the initial concentration of TBAB in the solution in this study, the CSG separation in this study is controlled by driving force (thermodynamics). The calculation of the hydrate formation during the $\mathrm{j}^{\text {th }}$ time unit is illustrated below.

As discussed previously, within the very short time interval of $\Delta t$, the formation of basic hydrate and its uptake of $\mathrm{CH}_{4}$ and $\mathrm{N}_{2}$ from gas phase can be considered as steady state. Their rates were determined according to the condition at the beginning of the $\mathrm{j}^{\text {th }}$ time unit, which is noted by subscript " $\mathrm{j}-1$ ". Furthermore, it is assumed that the composition of the final hydrate formed before the $\mathrm{j}^{\text {th }}$ time unit does not change during the $\mathrm{j}^{\text {th }}$ time unit; this is based on the experimental observation that once final hydrate is formed, its composition does not change with the change of the gas phase condition until it is melted. That is to say, once the basic hydrate is formed following Reaction 
1 (8), the uptake of $\mathrm{CH}_{4}$ and $\mathrm{N}_{2}$ by the hydrate formed during $\Delta \mathrm{t}$ reaches equilibrium

2 instantly based on the condition at that moment. The rate of TBAB consumption due to

3 the formation of basic semi-clathrate hydrate and the amount of TBAB consumed

$4 \quad$ within the time unit $\Delta t$ are: ${ }^{[76]}$

5

6

$$
\begin{aligned}
& \mathrm{r}_{\mathrm{TBAB}, \mathrm{j}}=\mathrm{k} \cdot \mathrm{N}_{\mathrm{H} 2 \mathrm{O}, \mathrm{j}-1} \cdot\left(\exp \left(\frac{-\Delta \mu_{\mathrm{j}-1}}{\mathrm{RT}}\right)-1\right) \\
& \mathrm{h}_{\mathrm{TBAB}, \mathrm{j}}=\mathrm{r}_{\mathrm{TBAB}, \mathrm{j}} \Delta \mathrm{t}
\end{aligned}
$$

where $\mathrm{k}\left(\mathrm{mol} \cdot \mathrm{mol}\right.$ water-1. $\left.\Delta \mathrm{t}^{-1}\right)$ is the rate constant of the formation of semi-clathrate basic hydrate. Correspondingly, the rates and amounts of the uptake of $\mathrm{CH}_{4}$ and $\mathrm{N}_{2}$ by the hydrate formed during the $\mathrm{j}^{\text {th }} \Delta \mathrm{t}$ are: ${ }^{[76]}$

$$
\begin{aligned}
& \mathrm{h}_{\mathrm{CH}_{4}, \mathrm{j}}=\mathrm{r}_{\mathrm{CH}_{4}, \mathrm{j}} \Delta \mathrm{t}=\alpha \cdot \theta_{\mathrm{CH}_{4}, \mathrm{j}} \cdot \mathrm{h}_{\mathrm{TBAB}, \mathrm{j}} \\
& \mathrm{h}_{\mathrm{N}_{2}, \mathrm{j}}=\mathrm{r}_{\mathrm{N}_{2}, \mathrm{j}} \Delta \mathrm{t}=\alpha \cdot \theta_{\mathrm{N}_{2}, \mathrm{j}} \cdot \mathrm{h}_{\mathrm{TBAB}, \mathrm{j}} \\
& \alpha=\frac{\lambda_{1}}{\lambda_{2}}
\end{aligned}
$$

$\alpha$ is the ratio of the numbers of the linked cavities to the TBAB semi-clathrate basic cavities. $\Delta \mu_{\mathrm{j}-1}$ is calculated by Eq. (15). According to the changes of the amounts of TBAB and water in solution and those of $\mathrm{CH}_{4}$ and $\mathrm{N}_{2}$ in gas phase, the condition after the $\mathrm{j}^{\text {th }}$ time unit is obtained.

It can be seen from Eqs. (34a) to (34d) that, when the hydrate formation driving force $(-\Delta \mu)$ is positive, the formation of hydrate and the uptake of $\mathrm{CH}_{4}$ and $\mathrm{N}_{2}$ in hydrate continue. When the hydrate formation driving force $(-\Delta \mu)$ becomes negative, the rate of hydrate formation becomes negative, which means the hydrate dissociates. The iteration in simulating the separation process terminates when the hydrate formation driving force $(-\Delta \mu)$ becomes close enough to zero according to the convergence criteria in Fig. 4.

After the $\mathrm{j}^{\text {th }} \Delta \mathrm{t}$, the molar amounts of $\mathrm{CH}_{4}$ and $\mathrm{N}_{2}$ in the gas phase are calculated 
as:

$2 \quad \mathrm{Ng}_{\mathrm{CH}_{4}, \mathrm{j}}=\mathrm{Ng}_{\mathrm{CH}_{4}, \mathrm{j}-1}-\mathrm{h}_{\mathrm{CH}_{4}, \mathrm{j}}$

$3 \quad \mathrm{Ng}_{\mathrm{N}_{2}, \mathrm{j}}=\mathrm{Ng}_{\mathrm{N}_{2}, \mathrm{j}-1}-\mathrm{h}_{\mathrm{N}_{2}, \mathrm{j}}$

4 The molar amounts of $\mathrm{CH}_{4}$ and $\mathrm{N}_{2}$ in the hydrate slurry are:

$\mathrm{Hg}_{\mathrm{CH}_{4}, \mathrm{j}}=\mathrm{Hg}_{\mathrm{CH}_{4}, \mathrm{j}-1}+\mathrm{h}_{\mathrm{CH}_{4}, \mathrm{j}}$

$6 \quad \mathrm{Hg}_{\mathrm{N}_{2}, \mathrm{j}}=\mathrm{Hg}_{\mathrm{N}_{2}, \mathrm{j}-1}+\mathrm{h}_{\mathrm{N}_{2}, \mathrm{j}}$

7 The amounts of $\mathrm{TBAB}$ and $\mathrm{H}_{2} \mathrm{O}$ in the liquid phase become:

$8 \quad \mathrm{~N}_{\mathrm{TBAB}, \mathrm{j}}=\mathrm{N}_{\mathrm{TBAB}, \mathrm{j}-1}-\mathrm{h}_{\mathrm{TBAB}, \mathrm{j}}$

$9 \quad \mathrm{~N}_{\mathrm{H}_{2} \mathrm{O}, \mathrm{j}}=\mathrm{N}_{\mathrm{H}_{2} \mathrm{O}, \mathrm{j}-1}-\frac{1}{\lambda_{2}} \mathrm{~h}_{\mathrm{TBAB}, \mathrm{j}}$

Due to above changes, the compositions of the gas and liquid phases are changed

11 as follows:

12

$$
\mathrm{y}_{\mathrm{CH}_{4}, \mathrm{j}}=\frac{\mathrm{Ng}_{\mathrm{CH}_{4}, \mathrm{j}}}{\mathrm{Ng}_{\mathrm{CH}_{4}, \mathrm{j}}+\mathrm{Ng}_{\mathrm{N}_{2}, \mathrm{j}}}
$$

13

$$
y_{N_{2}, j}=\frac{\mathrm{Ng}_{\mathrm{N} 2, \mathrm{j}}}{\mathrm{Ng}_{\mathrm{CH}_{4}, \mathrm{j}}+\mathrm{Ng}_{\mathrm{N}_{2}, \mathrm{j}}}
$$

14

$$
\mathrm{x}_{\mathrm{CH}_{4}, \mathrm{j}}=\frac{\mathrm{Hg}_{\mathrm{CH}_{4}, \mathrm{j}}}{\mathrm{Hg}_{\mathrm{CH}_{4}, \mathrm{j}}+\mathrm{Hg}_{\mathrm{N}_{2}, \mathrm{j}}}
$$

$$
\mathrm{X}_{\mathrm{N}_{2}, \mathrm{j}}=\frac{\mathrm{Hg}_{\mathrm{N} 2, \mathrm{j}}}{\mathrm{Hg}_{\mathrm{CH}_{4}, \mathrm{j}}+\mathrm{Hg}_{\mathrm{N}_{2}, \mathrm{j}}}
$$

$$
\mathrm{X}_{\mathrm{TBAB}, \mathrm{j}}=\frac{\mathrm{N}_{\mathrm{TBAB}, \mathrm{j}}}{\mathrm{N}_{\mathrm{TBAB}, \mathrm{j}}+\mathrm{N}_{\mathrm{H}_{2} \mathrm{O}, \mathrm{j}}}
$$

$$
\mathrm{w}_{\mathrm{TBAB}, \mathrm{j}}=\frac{\mathrm{x}_{\mathrm{TBAB}, \mathrm{j}} \cdot \mathrm{M}_{\mathrm{TBAB}}}{\mathrm{x}_{\mathrm{TBAB}, \mathrm{j}} \cdot \mathrm{M}_{\mathrm{TBAB}}+\left(1-\mathrm{x}_{\mathrm{TBAB}, \mathrm{j}}\right) \cdot \mathrm{M}_{\mathrm{H}_{2} \mathrm{O}}}
$$

$$
V_{d, j}=\frac{R \cdot\left(\mathrm{Hg}_{\mathrm{CH}_{4}, \mathrm{j}}+\mathrm{Hg}_{\mathrm{N}_{2}, \mathrm{j}}\right) \cdot \mathrm{Z}_{\mathrm{d}, \mathrm{stp}} \cdot \mathrm{T}_{\mathrm{stp}}}{\mathrm{P}_{\mathrm{stp}}}
$$

$$
V_{r, j}=\frac{R \cdot\left(\mathrm{Ng}_{\mathrm{CH}_{4}, \mathrm{j}}+\mathrm{Ng}_{\mathrm{N}_{2, j}}\right) \cdot \mathrm{Z}_{\mathrm{r}, \mathrm{stp}} \cdot \mathrm{T}_{\mathrm{stp}}}{\mathrm{P}_{\mathrm{stp}}}
$$

The calculation flow chart is shown in Fig. 5. In order to make it convenient for industrial application, mass fraction was used instead of mole fraction as the calculation 
1 import data. $Z_{\mathrm{r}, \mathrm{stp}}$ is the compressibility factor of the residual gas under standard condition $(273.15 \mathrm{~K}, 101325 \mathrm{~Pa})$. Visual basic 6.0 was used to edit the iterative computation. It also can be edited by MATLAB or any other software which can use for iterative computation.

In above simulation calculation, the total gas uptake is obtained by numeric addition (Eq. 46a) as the approximation of Eq. (46b):

$$
\begin{aligned}
& \mathrm{N}_{\mathrm{d}}=\sum_{j}^{\mathrm{t}_{\mathrm{eq}} / \Delta \mathrm{t}}\left(\mathrm{r}_{\mathrm{CH} 4, \mathrm{j}}+\mathrm{r}_{\mathrm{N} 2, \mathrm{j}}\right) \Delta \mathrm{t} \\
& \mathrm{N}_{\mathrm{d}}=\int_{0}^{\mathrm{t}_{\mathrm{eq}}}\left(\mathrm{r}_{\mathrm{CH}_{4}}+\mathrm{r}_{\mathrm{N}_{2}}\right) \mathrm{dt}
\end{aligned}
$$

In a practical hydrate formation process, variables such as gas composition and hydrate formation rate change continuously. In the modeling calculation, they were assumed remaining constant during each $\Delta \mathrm{t}$. The accuracy of the numeric calculation by Eq. 35a depends on the values of the changes of the variables such as gas composition and hydrate formation rate during each $\Delta \mathrm{t}$. When the changes of the variables during each $\Delta \mathrm{t}$ are small enough, the difference between Eq. (46a) and Eq. (46b) can be ignored, which leads to a good accuracy of the numeric calculation by Eq. (46a). Conversely, large changes of the variables during each $\Delta \mathrm{t}$ leads to a great difference between Eq. (46a) and Eq. (46b), which leads to a poor accuracy of the numeric calculation by Eq. 35a. The values of the changes of the variables during each $\Delta \mathrm{t}$ are determined by $\mathrm{k} . \mathrm{k}\left(\mathrm{mol} \cdot \mathrm{mol} \mathrm{water} \mathrm{r}^{-1} \cdot \Delta \mathrm{t}^{-1}\right)$ is the hydrate forming rate parameter. The purpose of this study was to investigate the final equilibrium gas uptake rather than the reaction kinetics, because the latter was affected by many factors in the engineering practice. The results of numeric calculations for a case at $281.15 \mathrm{~K}, 2.5 \mathrm{MPa}$, initial concentration of $\mathrm{TBAB}$ in solution at $0.901 \mathrm{~mol} \%$ and $\mathrm{CSG} /$ liquid ratio at $30 \mathrm{NL} / \mathrm{L}$, with different of $\mathrm{k} \cdot \Delta \mathrm{t}$ is presented in Table 5 , which demonstrates the $\mathrm{k} \cdot \Delta \mathrm{t}$ for the numeric calculation. 
It can be seen from Table 5 that the steps needed to reach the chemical equilibrium increases dramatically, from $31 \mathrm{steps}$ when $\mathrm{k} \cdot \Delta \mathrm{t}$ is $0.1 \mathrm{~mol} \cdot \mathrm{mol} \mathrm{water}^{-1}$ to $35336 \mathrm{steps}$ when $\mathrm{k} \cdot \Delta \mathrm{t}$ is $0.00004 \mathrm{~mol} \cdot \mathrm{mol} \mathrm{water}^{-1}$. Correspondingly, the calculation results ( $\mathbf{x C H 4}$, усн4 and GSCHS) change with the decrease of $\mathrm{k} \cdot \Delta \mathrm{t}$ at first, and become steady. The results practically do not change when $\mathrm{k} \cdot \Delta \mathrm{t}$ ratio is below $0.0001 \mathrm{~mol} \cdot \mathrm{mol} \mathrm{water}^{-1}$. This is because the values of the changes of the variables during each $\Delta t$ decease with the decrease in $\mathrm{k}$. When $\mathrm{k}$ is $0.1 \mathrm{~mol} \cdot \mathrm{mol} \mathrm{water}^{-1} \cdot \Delta \mathrm{t}^{-1}$, it takes only 31 iterations (31 $\left.\Delta \mathrm{t}\right)$ for the separation to reach equilibrium in modeling calculation. The maximum change during each $\Delta \mathrm{t}$ is $1.686 \mathrm{~mol} \%$ for the concentration of $\mathrm{CH}_{4}$ in the hydrate phase, 3.799 mole $\%$ for the concentration of the $\mathrm{CH}_{4}$ in the gas phase and $4.715 \mathrm{NL} / \mathrm{L}$ for GSCHGS. These changes can make great difference in the hydrate formation rate and the $\mathrm{CH}_{4}$ hydrate capture selectivity. The hydrate formation rate and the $\mathrm{CH}_{4}$ hydrate capture selectivity in the $\mathrm{j}^{\text {th }} \Delta \mathrm{t}$ are great different from those in the $(\mathrm{j}-1)^{\mathrm{th}} \Delta \mathrm{t}$ in Eq.(46a) while the hydrate formation rate and the $\mathrm{CH}_{4}$ hydrate capture selectivity in the $\mathrm{j}^{\text {th }} \mathrm{dt}$ are almost the same with those in the $(\mathrm{j}-1)^{\text {th }} \mathrm{dt}$ in Eq. (46b). It can be seen from Table 5, as the $\mathrm{k}$ decreases, the values of the changes of the variables during each $\Delta \mathrm{t}$ decrease, the difference between Eq. (46a) and Eq. (46b) has no influence on the calculation results (хсн4, yCH4 and GSCHS) when $\mathrm{k} \cdot \Delta \mathrm{t}$ is below $0.0001 \mathrm{~mol} \cdot \mathrm{mol} \mathrm{water}^{-1}$. Though a smaller $\mathrm{k}$ leads to a better accuracy of the numeric calculation by Eq. (46a), it also leads to a larger number of iterations $\left(t_{\text {eq }} / \Delta \mathrm{t}\right)$ in calculation, especially leads to a huge number of the iterations in multistage separation. Based on calculations, for all operating conditions in this study, the influence of the difference between Eq. (46a) and Eq.(46b) on modeling calculation can be ignored when $\mathrm{k} \cdot \Delta \mathrm{t}$ is below $0.00008 \mathrm{~mol} \cdot \mathrm{mol} \mathrm{water}^{-1}$. In this study, the hydrate formation rate parameter $\mathrm{k}$ was determined as 0.00004 mol·mol water ${ }^{-1} \cdot \Delta \mathrm{t}^{-1}$. 
Average relative deviation (ARD), average relative variance (ARV), maximum relative deviation (MRD) and Goodness of fit (GF) are applied in order to calculate the deviation between model results and experimental data. They are calculated by Eqs. (47a) to $(47 d)$.

$$
\mathrm{ARD}=\frac{\sum_{\mathrm{i}}^{\mathrm{n}}\left|\frac{\text { Experimental value- Calculated value }}{\text { Experimental value }}\right|}{\mathrm{n}} \cdot 100 \%
$$

$$
\begin{aligned}
& \mathrm{MRD}=\max \left(\left|\frac{\text { Experimental value }- \text { Calculated value }}{\text { Experimental value }}\right|\right) \cdot 100 \% \\
& \mathrm{GF}=\frac{\sum_{i}^{n}(\text { Experimental value- Calculated value })^{2}}{\sum_{i}^{n}\left(\text { Experimental value }-\sum_{i}^{n} \text { Experimental value } / n\right)^{2}} \cdot 100 \%
\end{aligned}
$$

where $\mathrm{n}$ denotes the number of the total experiments. Smaller ARD, ARV and MRD show better prediction accuracy of the model. The GF is used to present the goodness of the model in showing the effect of each factor on the hydrate based separation and gas storage, GF normally has values between 0 and 1. A value of GF close to 1 means that the model can predict the effect of a factor on hydrate based separation accurately.

\subsection{Multistage separation modeling}

Since the single stage separation is not sufficient to meet industrial requirements, multistage operation must be carried out if this process is put into practice. Experimental investigation of the multistage operation ${ }^{[24,77]}$ is complex and difficult to include the circulation of the gas flow with low target component content. For the latter reason, the RF decreases quickly as the number of separation stages increases. For example, in one-way operation, the RF of three-stage separation is only $12.5 \mathrm{~mol} \%$ for $50 \% \mathrm{RF}$ in one stage separation. In the work by Wang et al. ${ }^{[13]}$, the inclusion of the circulation of the gas flow with low target component content makes it necessary to 
1 carry out a series of experiments for any adjustment of the operation in order to gain

2 the knowledge of the performance of each operating unit, which makes the simulation

3 inconvenient in application. In this study, a computing method is proposed for the

4 simulation of multistage separation. The model CSG flows into a multistage separation

5 system (Fig. 6) where $\mathrm{CH}_{4}$ is concentrated to higher than $80 \mathrm{~mol} \%$ in the high $\mathrm{CH}_{4}$

6 content gas, and its content in the low $\mathrm{CH}_{4}$ content gas is reduced to lower than 10

$7 \mathrm{~mol} \%$. In the process, the final gas with concentrated $\mathrm{CH}_{4}$ is obtained from the bottom

8 operation stage as the dissociated gas, while the residual gas with low $\mathrm{CH}_{4}$ content is

9 obtained from the top operation stage (Fig. 6). For the middle stages, the feed includes

10 the dissociated gas from its upper stage and the residual gas from the lower stage, and

11 the separated gases are further separated as the feeds of the upper and lower stages. In

12 the modelling calculation, the performance of each stage is predicted by the single stage 13 separation model..

The calculation sequence of the multistage separation is as follows: (1) Stage 1, (2) Stages 2_1 and 2_2; (3) Stages 3_1 and 3_2. Then the calculation is repeated for the next time unit from (1) again. $\mathrm{i}$ is the number of iteration. In multistage separation, $\mathrm{V}$ is the volume $(273.15 \mathrm{~K}, 101325 \mathrm{~Pa})$ of the gas flowing into the separation operating unit. $\mathrm{zz}$ is the component concentration in the gas flowing into the separation operating unit. $\mathrm{x}$ is the component concentration of the dissociated gas flowing out the separation operating unit. "ratio" is the ratio of the feed gas volume to the TBAB solution volume under $273.15 \mathrm{~K}, 101325 \mathrm{~Pa}$. And their subscripts are the operating units they belonged and the number of the iteration. When the iteration is at its first loop computation, there is no gas sent back to mixers:

$$
\begin{aligned}
& \mathrm{zz}_{\mathrm{CH}_{4}, 1,1}=\mathrm{y}_{\mathrm{CH}_{4}, \mathrm{CSG}} \\
& \mathrm{V}_{1,1}=\mathrm{V}_{\mathrm{CSG}}
\end{aligned}
$$




$$
\begin{array}{ll}
1 & \mathrm{zZ}_{\mathrm{CH}_{4}, 2 \_1,1}=\mathrm{y}_{\mathrm{CH}_{4}, 1,1} \\
2 & \mathrm{~V}_{2 \_1,1}=\mathrm{V}_{\mathrm{r} 1,1} \\
3 & \mathrm{zz}_{\mathrm{CH}_{4}, 2 \_2,1}=\mathrm{x}_{\mathrm{CH}_{4}, 1,1} \\
4 & \mathrm{~V}_{2 \_2,1}=\mathrm{V}_{\mathrm{d} 1,1}
\end{array}
$$

5 When the iteration goes to the i th loop computation, for Separation stage 1:

6

$$
\mathrm{N}_{\mathrm{CH}_{4}, 1, \mathrm{i}}=\left(\frac{\mathrm{P} \cdot \mathrm{V} \cdot \mathrm{y}_{\mathrm{CH}_{4}}}{\mathrm{R} \cdot \mathrm{Z} \cdot \mathrm{T}}\right)_{\mathrm{CSG}}+\left(\frac{\mathrm{P} \cdot \mathrm{V} \cdot \mathrm{x}_{\mathrm{CH}_{4}}}{\mathrm{R} \cdot \mathrm{Z} \cdot \mathrm{T}}\right)_{\mathrm{d} 2_{-} 1, \mathrm{i}-1}+\left(\frac{\mathrm{P} \cdot \mathrm{V} \cdot \mathrm{y}_{\mathrm{CH}_{4}}}{\mathrm{R} \cdot \mathrm{Z} \cdot \mathrm{T}}\right)_{\mathrm{r} 2 \_2, \mathrm{i}-1}
$$

$7 \quad \mathrm{~N}_{\mathrm{N}_{2}, 1, \mathrm{i}}=\left(\frac{\mathrm{P} \cdot \mathrm{V} \cdot \mathrm{y}_{\mathrm{N}_{2}}}{\mathrm{R} \cdot \mathrm{Z} \cdot \mathrm{T}}\right)_{\mathrm{CSG}}+\left(\frac{\mathrm{P} \cdot \mathrm{V} \cdot \mathrm{x}_{\mathrm{N}_{2}}}{\mathrm{R} \cdot \mathrm{Z} \cdot \mathrm{T}}\right)_{\mathrm{d}_{2} \_1, \mathrm{i}-1}+\left(\frac{\mathrm{P} \cdot \mathrm{V} \cdot \mathrm{y}_{\mathrm{N}_{2}}}{\mathrm{R} \cdot \mathrm{Z} \cdot \mathrm{T}}\right)_{\mathrm{r} 2 \_, \mathrm{i}-1}$

$8 \quad \mathrm{zZ}_{\mathrm{CH}_{4}, 1, \mathrm{i}}=\mathrm{N}_{\mathrm{CH}_{4}, 1, \mathrm{i}} /\left(\mathrm{N}_{\mathrm{CH}_{4}, 1, \mathrm{i}}+\mathrm{N}_{\mathrm{N}_{2}, 1, \mathrm{i}}\right)$

$9 \quad \mathrm{~V}_{1, \mathrm{i}}=\left(\frac{\left(\mathrm{N}_{\mathrm{CH}_{4,1, i}}+\mathrm{N}_{\mathrm{N}_{2,1, i}}\right) \cdot \mathrm{Z} \cdot \mathrm{R} \cdot \mathrm{T}}{\mathrm{P}}\right)_{\text {stp }}$

$10 \quad \mathrm{~V}_{\text {sol1,i }}=\mathrm{V}_{1, \mathrm{i}} /$ ratio $_{1}$

For separation stage 2_1:

$\mathrm{N}_{\mathrm{CH}_{4}, 2_{-} 1, \mathrm{i}}=\left(\frac{\mathrm{P} \cdot \mathrm{V} \cdot \mathrm{y}_{\mathrm{CH}_{4}}}{\mathrm{R} \cdot \mathrm{Z} \cdot \mathrm{T}}\right)_{\mathrm{r} 1, \mathrm{i}}+\left(\frac{\mathrm{P} \cdot \mathrm{V} \cdot \mathrm{x}_{\mathrm{CH}_{4}}}{\mathrm{R} \cdot \mathrm{Z} \cdot \mathrm{T}}\right)_{\mathrm{d}_{3}{ }_{-}, \mathrm{i}-1}$

$\mathrm{N}_{\mathrm{N}_{2}, 2 \_1, \mathrm{i}}=\left(\frac{\mathrm{P} \cdot \mathrm{V} \cdot \mathrm{y}_{\mathrm{N}_{2}}}{\mathrm{R} \cdot \mathrm{Z} \cdot \mathrm{T}}\right)_{\mathrm{r} 1, \mathrm{i}}+\left(\frac{\mathrm{P} \cdot \mathrm{V} \cdot \mathrm{x}_{\mathrm{N}_{2}}}{\mathrm{R} \cdot \mathrm{Z} \cdot \mathrm{T}}\right)_{\mathrm{d} 3_{-} 1, \mathrm{i}-1}$

$\mathrm{ZZ}_{\mathrm{CH}_{4}, 2_{-} 1, \mathrm{i}}=\mathrm{N}_{\mathrm{CH}_{4}, 2 \_1, \mathrm{i}} /\left(\mathrm{N}_{\mathrm{CH}_{4}, 2 \_1, \mathrm{i}}+\mathrm{N}_{\mathrm{N}_{2}, 2_{-} 1, \mathrm{i}}\right)$

$\mathrm{V}_{2 \_1, \mathrm{i}}=\left(\frac{\left(\mathrm{N}_{\mathrm{CH}_{4}, 2 \_1, \mathrm{i}}+\mathrm{N}_{\mathrm{N}_{2,2 \_}, \mathrm{i}}\right) \cdot \mathrm{Z} \cdot \mathrm{R} \cdot \mathrm{T}}{\mathrm{P}}\right)_{\text {stp }}$

$\mathrm{V}_{\text {sol2_1,i }}=\mathrm{V}_{2 \_1, \mathrm{i}} /$ ratio $_{2 \_1}$

For separation stage 2_2:

$\mathrm{N}_{\mathrm{CH}_{4}, 2,2, \mathrm{i}}=\left(\frac{\mathrm{P} \cdot \mathrm{V} \cdot \mathrm{x}_{\mathrm{CH}_{4}}}{\mathrm{R} \cdot \mathrm{Z} \cdot \mathrm{T}}\right)_{\mathrm{d} 1, \mathrm{i}}+\left(\frac{\mathrm{P} \cdot \mathrm{V} \cdot \mathrm{y}_{\mathrm{CH}_{4}}}{\mathrm{R} \cdot \mathrm{Z} \cdot \mathrm{T}}\right)_{\mathrm{r} 3_{-} 2, \mathrm{i}-1}$

$9 \quad \mathrm{~N}_{\mathrm{N}_{2}, 2 \_2, \mathrm{i}}=\left(\frac{\mathrm{P} \cdot \mathrm{V} \cdot \mathrm{x}_{\mathrm{N}_{2}}}{\mathrm{R} \cdot \mathrm{Z} \cdot \mathrm{T}}\right)_{\mathrm{d} 1, \mathrm{i}}+\left(\frac{\mathrm{P} \cdot \mathrm{V} \cdot \mathrm{y}_{\mathrm{N}_{2}}}{\mathrm{R} \cdot \mathrm{Z} \cdot \mathrm{T}}\right)_{\mathrm{r} 3 \_2, \mathrm{i}-1}$

20

$\mathrm{Zz}_{\mathrm{CH}_{4}, 2 \_2, \mathrm{i}}=\mathrm{N}_{\mathrm{CH}_{4}, 2 \_2, \mathrm{i}} /\left(\mathrm{N}_{\mathrm{CH}_{4}, 2 \_2, \mathrm{i}}+\mathrm{N}_{\mathrm{N}_{2}, 2 \_ \text {_ }, \mathrm{i}}\right)$

21

$\mathrm{V}_{2 \_ \text {_, i }}=\left(\frac{\left(\mathrm{N}_{\mathrm{CH}_{4}, 2 \_2, \mathrm{i}}+\mathrm{N}_{\mathrm{N}_{2,2} \_, \mathrm{i}}\right) \cdot \mathrm{Z} \cdot \mathrm{R} \cdot \mathrm{T}}{\mathrm{P}}\right)_{\text {stp }}$

22

$\mathrm{V}_{\text {sol2_2,i }}=\mathrm{V}_{2 \_2, \mathrm{i}} /$ ratio $_{2 \_2}$ 
$3 \quad \mathrm{~V}_{3 \_1, \mathrm{i}}=\mathrm{V}_{\mathrm{r} 2 \_1, \mathrm{i}}$

$4 \quad \mathrm{~V}_{\text {sol3_1,i }}=\mathrm{V}_{3 \_1, \mathrm{i}} / \mathrm{ratio}_{3 \_1}$

For separation stage 3_2:

$$
\mathrm{V}_{3 \_2, \mathrm{i}}=\mathrm{V}_{\mathrm{d} 2 \_2, \mathrm{i}}
$$

$$
\mathrm{V}_{\text {sol3_2,i }}=\mathrm{V}_{3 \_2, \mathrm{i}} / \text { ratio }_{3 \_2}
$$

Since the multistage separation system will finally reach dynamically stable, there is a mass balance between the gas flowing in and the gas flowing out after it reaches dynamically stable:

$$
\begin{aligned}
& \mathrm{N}_{\mathrm{CSG}}=\mathrm{N}_{\mathrm{r}_{3} \_1}+\mathrm{N}_{\mathrm{d} 3 \_2} \\
& \mathrm{~N}_{\mathrm{CSG}} \cdot \mathrm{y}_{\mathrm{CH}_{4}, \mathrm{CSG}}=\mathrm{N}_{\mathrm{r} 3 \__{1} 1} \cdot \mathrm{y}_{\mathrm{CH}_{4}, 3 \_1}+\mathrm{N}_{\mathrm{d} 3 \_2} \cdot \mathrm{x}_{\mathrm{CH}_{4}, 3 \_2} \\
& \text { Erro }=\mathrm{N}_{\mathrm{CSG}} \cdot \mathrm{y}_{\mathrm{CH}_{4}, \mathrm{CSG}}-\mathrm{N}_{\mathrm{r} 3 \__{-} 1} \cdot \mathrm{y}_{\mathrm{CH}_{4}, 3_{-} 1}-\mathrm{N}_{\mathrm{d}_{3} 2} \cdot \mathrm{x}_{\mathrm{CH}_{4}, 3 \_2} \\
& \operatorname{Rec}=V_{1} / V_{\text {CSG }} \\
& \operatorname{Ref}=\left(V_{\text {back }} / V_{\text {in }}\right) \times 100 \%
\end{aligned}
$$

Recycle ratio(Rec) is the efficiency of the multistage separation, and large recycle ratio means that the moles of the CSG meeting the demand after multistage separation is much smaller than the moles of gas recycled in the system. Reflex ratio(Ref) is the efficiency of the operating unit, and large reflex ratio leads to the low efficiency of the operating unit. Vback is the volume of the gas flowing out of the operating unit to the previous stage. $\mathrm{V}_{\text {in }}$ is the volume of the gas flowing into the operating unit. The multistage separation calculation flow chart is shown in Fig. 7. 


\section{4. Results and discussion}

\section{4.1 The viscosity of TBAB solution and the}

3 interfacial tension between the TBAB solution

4 and CSG

5

As described in the Introduction section, the addition of additives into water phase can affect gas hydrate formation in different ways. On one hand, an additive may affect the equilibrium distribution of gas species in gas and liquid phases. On the other hand, it may affect the mass transfer between the two phases or in the liquid phase by changing the interfacial tension between the two phases or affecting viscosity of the liquid phase. Knowledge on the viscosity and interfacial tension of the solutions is beneficial to the better understanding of the hydrate formation and separation mechanisms. Tables 6 and 7 present the viscosity of the TBAB solutions and their interfacial tension with CSG gas.

As shown in Table 6, the viscosity of pure water is consistent with the data reported in the literature. ${ }^{[78]}$ The addition of TBAB solution increases the viscosity of the liquid phase; the viscosity of the liquid phase increases with the increase of TBAB concentration in the solution and decreases with the increase in temperature. The results agree with those obtained by Sinha ${ }^{[79]}$. From kinetics, this increased viscosity is not favorable to the mass transfer of gas species in the liquid phase.

According to Table 7, the addition of TBAB into water decreases the interfacial tension between the $\mathrm{CSG}$ of $34.6 \mathrm{~mol} \% \mathrm{CH}_{4}$ and the liquid phase, and the interfacial tension decreases with the increase in the $\mathrm{TBAB}$ concentration in the solution and with 
1 the increase in pressure. These trends agree with the changes of interfacial tension between $\mathrm{CO}_{2}+\mathrm{N}_{2}$ and TBAB solution obtained by Akiba ${ }^{[80]}$. This means that addition of TBAB into water favors the mass transfer of gas species from CSG into liquid phase.

\subsection{Single stage separation of CSG by hydrate}

\section{formation}

\subsubsection{Effect of CSG/liquid ratio on the separation of CSG}

The CSG/liquid ratio is expressed as the ratio of the volume of CSG (273.15 $\mathrm{K}, 101325 \mathrm{~Pa}$ ) to the volume of TBAB solution at the beginning of separation (CL). The effect of $\mathrm{CL}$ on the performance of the $\mathrm{CH}_{4}$ recovery by hydrate formation was carried out at $281.15 \mathrm{~K}$ and $2.5 \mathrm{MPa}$ with $0.901 \mathrm{~mol} \% \mathrm{TBAB}$ solution. The experimental results are presented in Fig. 8. It can be seen from Fig. 8a, both SF and $\mathrm{RF}$ of $\mathrm{CH}_{4}$ decrease as CL increases, which is in agreement with the results of Wang et al. ${ }^{[13]}$ in CSTR operation. From Fig. 8b, ХCH4 increases from $47.0( \pm 0.3) \mathrm{mol} \%$ with $\mathrm{CL}$ at $20 \mathrm{NL} / \mathrm{L}$ to $53.7( \pm 0.3) \mathrm{mol} \%$ with $\mathrm{CL}$ at $60 \mathrm{NL} / \mathrm{L}$, which is a significant enrichment from 34.6 mol\%. yCH4 increases from $20.3( \pm 0.2)$ mol\% to $29.3( \pm 0.2)$ mol\% with the increase of CL. Due to the reduction of SF, усн4 increases with the increase in CL. Хсн4 depends on the $\mathrm{CH}_{4}$ capture selectivity of the hydrate $\left(\theta_{\mathbf{C H} 4} / \theta_{\mathbf{N} 2}\right)$. Under constant operating pressure, the increase in $\mathrm{yCH}_{4}$ leads to an increase in $\theta_{\mathbf{C H} 4} / \theta_{\mathrm{N} 2}$ and increase in $\mathbf{X C H}_{\mathbf{C}}$.

GSCHS increases from $10.7( \pm 0.2) \mathrm{NL} / \mathrm{L}$ with $\mathrm{CL}$ at $20 \mathrm{NL} / \mathrm{L}$ to $13.2( \pm 0.2) \mathrm{NL} / \mathrm{L}$ with CL at $60 \mathrm{NL} / \mathrm{L}$. This trend agrees with the findings of Wang et al. ${ }^{[13]}$ in CSTR operation and Cai et al. ${ }^{[9]}$ in semi batch operation. Since $\mathrm{CH}_{4}$ is more easily captured into hydrate than $\mathrm{N}_{2}$, the increase in $\theta_{\mathbf{C H} 4}$ overrides the decrease of $\theta_{\mathrm{N} 2}$ with the increase of yCH4, leading to the increases in $\theta_{\mathbf{C H} 4}+\theta_{\mathbf{N} 2}$ and so GSCHS.

Fig. $8 \mathrm{~b}$ also present the modeling results under corresponding conditions. The 
1 simulation of the separation process predicts well on the effect of CL on the compositions of dissociated gas and residual gas. The predicted effect of CL on GCSHS is milder than that experimentally measured. The ARD, ARV and MRD of all data in Fig. $8 \mathrm{~b}$ are $4.12 \%, 0.0308$ and $11.00 \%$, respectively. The GF is 0.90 for $\mathbf{x} \mathbf{C H} 4,0.83$ for yсH4 and 0.34 for GCSHS. The higher deviation of GCSHS may be because in model calculation, the interaction between $\mathrm{TBAB}$ in basic cavity and the gas molecules in linked cavity ( $\mathrm{A}_{\mathbf{C H} 4}$ and $\mathrm{A}_{\mathbf{N} 2}$ ) is constant and not influenced by the concentrations of $\mathrm{CH}_{4}$ and $\mathrm{N}_{2}$ in hydrate, but in actual process of the TBAB semi-clathrate hydrate formation, the change of the interaction cannot be ignored. In order to improve the GF in GCSHS prediction, the optimization of $\mathrm{A}_{\mathbf{C H} 4}$ and $\mathrm{A}_{\mathbf{N} 2}$ and a larger experiment database can be considered in the future work.

Since liquid cooling is the most energy demanding in hydrate separation, a higher $\mathrm{CL}$ reduces the amount of TBAB solution used, which results in lower energy consumption on cooling TBAB solution. On the other hand, the capacity of hydrate based separation is limited by the amount of TBAB solution used. Too high CL reduces the separation factor (SF) and the recovery rate of $\mathrm{CH}_{4}(\mathrm{RF})$. When the separation efficiency and the recovery rate of $\mathrm{CH}_{4}$ are too low to meet the industry requirements, more separation stages are demanded. Comprehensive consideration is needed to determine an optimum CL for the recovery of $\mathrm{CH}_{4}$.

In the CL range in Fig. 8, the $\mathrm{CH}_{4}$ concentration was increased by $12.4-19.1$ mol\%. To concentrate $\mathrm{CH}_{4}$ from $34.6 \mathrm{~mol} \%$ to $80 \mathrm{~mol} \%$ would need a three-stage separation process, by which the average increase of $\mathrm{XCH}_{\mathbf{4}}$ in each separation stage is about $15 \mathrm{~mol} \%$. Taking the separation efficiency and recovery rate into consideration, $30 \mathrm{NL} / \mathrm{L}$ was chosen as the CL in the following experiments. 


\subsubsection{Effect of TBAB concentration on the separation of CSG}

The effect of the initial TBAB concentration in the solution on the performance of the separation was examined at $281.15 \mathrm{~K}$ and $2.5 \mathrm{MPa}$ with $\mathrm{CL}$ at $30 \mathrm{NL} / \mathrm{L}$. The experimental results with corresponding modeling results are presented in Fig. 9. GSCHS increases from $7.5( \pm 0.2) \mathrm{NL} / \mathrm{L}$ at $0.617 \mathrm{~mol} \%$ TBAB to $13.9( \pm 0.2) \mathrm{NL} / \mathrm{L}$ at $1.052 \mathrm{~mol} \%$ TBAB. Because the increase in the initial concentration of the TBAB in the solution leads to an increase in the driving force of the hydrate formation, which results in the increase in the moles of hydrate. Correspondingly, the RF increases with the increase in $\mathrm{TBAB}$ concentration. Preferential $\mathrm{CH}_{4}$ capture in the hydrate slurry $\left(\theta_{\mathbf{C H} 4} / \theta_{\mathbf{N} 2}>\mathrm{yCH}_{\mathbf{C}} / \mathrm{y}_{\mathbf{N} 2}\right)$ results in the decrease in $\mathbf{y C H}_{\mathbf{C}}$. The larger moles of the hydrate form, the greater the decrease in the усн4. усн4 decreases from $28.1( \pm 0.2)$ mol\% at $0.617 \mathrm{~mol} \%$ TBAB to $22.7( \pm 0.1) \mathrm{mol} \%$ at $1.052 \mathrm{~mol} \%$ TBAB. Under the reduced $\mathrm{yCH}_{4}$ condition, the gas capture selectivity of hydrate $\left(\theta_{\mathbf{C H} 4} / \theta_{\mathbf{N} 2}\right)$ decreases, more $\mathrm{N}_{2}$ is also captured in the hydrate, causing reduction of Хсн4. Хсн4 decreases from $53.9( \pm 0.2)$ mol\% to $48.4( \pm 0.3) \mathrm{mol} \%$.

SF increases with the increase in TBAB concentration at first and then decreases, which agrees with the findings of Wang et al. ${ }^{[13]}$ in CSTR operation and Zhong et al. ${ }^{[11]}$ in semi batch operation. In the range of low TBAB concentration, the selectivity of $\mathrm{CH}_{4}$ capture in hydrate is high, resulting in higher $\mathrm{SF}$ with increasing TBAB concentration. However, in the range of high TBAB concentration, the selectivity of $\mathrm{CH}_{4}$ capture decreases due to the significant decrease of ycH4, resulting in decrease of $\mathrm{SF}$ with the increase in the TBAB in solution. A peak SF is formed at TBAB concentration about $0.9 \mathrm{~mol} \%$. This $\mathrm{TBAB}$ concentration of peak SF is expected to become higher at higher CL, which can be confirmed in more detailed modeling work in the future. 
It can be seen from Fig. $9 \mathrm{~b}$ that the modeling results of the separation performance at different $\mathrm{TBAB}$ concentrations match the experimental results very well. The ARD, ARV and MRD of all data in Fig. $9 \mathrm{~b}$ are 2.61\%, 0.0109 and 5.95\%, respectively. The GF is 0.61 for хсн4, 0.81 for усH4 and 0.98 for GSCHS. The goodness of fit of хCH4 is slightly lower than that of GSCHS and усн4, and the effect of ХтвAB,0 On хсн4 predicted by modeling is not as strong as that in experiments.

There are three physical resistances for the gas species to be captured in gas hydrate: diffusion in the gas phase, cross the gas-liquid interface and in the liquid to reach basic hydrate grain surface. As presented in section 4.1, increasing TBAB concentration in solution causes a decrease in the interfacial tension but increase in solution viscosity, which decreases the diffusion resistance of the gas species cross the interface but increases the diffusion resistance in solution. The good fitting of the modeling results with experimental data in the separation performance shows that above diffusion processes did not affect the hydrate formation significantly, and the assumption of adsorption equilibrium of $\mathrm{CH}_{4}$ and $\mathrm{N}_{2}$ in hydrate is acceptable. The phenomenon of lower $\mathrm{CH}_{4}$ concentration near the hydrate than that in the bulk phase $[\mathbf{8 1}, \mathbf{8 2}]$ is not obvious in this work

Practical application of the CSG separation via hydrate formation requires that the TBAB solution has high GSCHS provided that the SF and RF satisfy definite specification. Thus, the high GSCHS at a high initial TBAB concentration in the solution is beneficial to achieving a high $\mathrm{CH}_{4}$ recovery. However, хсн4 decreases along with the reduction of усн4 with the increase of $\mathrm{TBAB}$ concentration. Increasing $\mathrm{CL}$ simultaneously helps to maintain a high хсн4 but this will increase Усн4 and decrease RF. So, to achieve high $\mathrm{CH}_{4}$ recovery and high $\mathrm{x} \mathbf{C H} 4$, multistage separation is necessary. Using the $\mathrm{CL}$ at $30 \mathrm{NL} / \mathrm{L}$ in this series of experiments, the highest $\mathrm{SF}$ is achieved when 
the initial concentration of the TBAB in the solution is $0.901 \mathrm{~mol} \%$, and $\mathrm{xCH}_{4}$ is expected to meet the demand by three-stage separation. Taking the separation efficiency and recovery rate into consideration, $0.901 \mathrm{~mol} \%$ was chosen as the initial TBAB concentration in the following experiments.

\subsubsection{Effect of temperature on the separation of CSG}

Operating temperature affects not only the formation of basic hydrate, but also the adsorption of $\mathrm{CH}_{4}$ and $\mathrm{N}_{2}$ in the hydrate cavities. The effect of temperature on the performance of separation was examined at $2.5 \mathrm{MPa}$ with $\mathrm{CL}$ at $30 \mathrm{NL} / \mathrm{L}$ and TBAB concentration at $0.901 \mathrm{~mol} \% \mathrm{TBAB}$. The experimental results and modeling data are presented in Fig. 10. The separation performance is very sensitive to the change of temperature. GSCHS decreases from $13.1( \pm 0.3) \mathrm{NL} / \mathrm{L}$ at $280.15 \mathrm{~K}$ to $9.9( \pm 0.2) \mathrm{NL} / \mathrm{L}$ at $283.15 \mathrm{~K}$. The increase in operating temperature leads to the decrease of the occupation fraction of the linked cavities $\left(\theta_{\mathbf{C H} 4}+\theta_{\mathbf{N} 2}\right)$, so the moles of gas captured by per mole hydrate decreases, which results in the decrease in the GSCHS. The increase in operating temperature leads to the decrease in the moles of hydrate, which also leads to the decrease in the GSCHS. Caused by the preferential $\mathrm{CH}_{4}$ capture in the hydrate slurry, smaller GSCHS leads to smaller decrease in the concentration of the $\mathrm{CH}_{4}$ in the gas phase. So ycH4 increases from $22.8( \pm 0.2) \mathrm{mol} \%$ to $26.1( \pm 0.3) \mathrm{mol} \%$ with the increase of the operating temperature. $\mathrm{XCH}_{4}$ increases from $49.8( \pm 0.3) \mathrm{mol} \%$ to 52.1 $( \pm 0.2) \mathrm{mol} \%$, correspondingly. These changes caused significant decrease in RF and SF as the operating temperature increases.

As it can be seen from Fig. 10b, the experimental and modeling results match well. The ARD, ARV and MRD are $2.27 \%, 0.0101$, and $6.40 \%$, respectively. The GF is 0.57 for $\mathrm{XCH}_{4}, 0.51$ for $\mathrm{yCH} 4$ and 0.89 for GSCHS. The goodness of fit of gas compositions 
is not as good as those of the CSGHS.

It is well known that temperature is a major factor affecting the thermodynamics and kinetics of chemical reactions. Decreasing temperature favors formation of more basic hydrate and adsorption of more gases in unit amount of basic hydrate, which is consistent with the experimental data and modeling prediction. At a low temperature, the diffusion of gas species and hydrate formation are slower than at a higher temperature, but according to Fig. 10b, the experimentally achieved separation performance at low temperature is better than that predicted by process simulation. It illustrates that the kinetics of gas hydrate including mass transfer of gas species from gas to liquid phase is not the controlling stage in the separation process. The rate of gas hydrate formation is determined by that of formation of basic hydrate. In order to ensure the increase in the хсн4 meets the demand of the three- stage separation, $281.15 \mathrm{~K}$ was chosen as the operating temperature in the following experiments.

\subsubsection{Effect of pressure on the separation of CSG}

The effect of operating pressure on the performance of the separation by hydrate formation was carried out at $281.15 \mathrm{~K}$ with $\mathrm{CL}$ at $30 \mathrm{NL} / \mathrm{L}$ and $0.901 \mathrm{~mol} \% \mathrm{TBAB}$ in solution. The experimental and modelling results are presented in Fig. 11. GSCHS increases from $3.1( \pm 0.1) \mathrm{NL} / \mathrm{L}$ under $1 \mathrm{MPa}$ to $14.4( \pm 0.3) \mathrm{NL} / \mathrm{L}$ under $3.5 \mathrm{MPa}$. The increase in operating pressure leads to the increase of the occupation fraction of the linked cavities $\left(\theta_{\mathbf{C H} 4}+\theta_{\mathbf{N} 2}\right)$, so the moles of gas captured by per mole hydrate increases, which results in the decrease in the GSCHS. The increase in operating pressure leads to the increase in the moles of hydrate, which also leads to the increase in the GSCHS. Larger GSCHS leads to greater decrease in the concentration of the $\mathrm{CH}_{4}$ in the gas phase. Усн4 decreases from $32.3( \pm 0.1)$ mol\% to $21.4( \pm 0.2)$ mol\%. ХCH4 also decreases 
1 from $54.7( \pm 0.1) \mathrm{mol} \%$ to $48.9( \pm 0.3) \mathrm{mol} \%$ due to the decrease in the selectivity

$2\left(\theta_{\mathbf{C H} 4} / \theta_{\mathrm{N} 2}\right)$ caused by the decrease of $\mathrm{y}_{\mathbf{C H} 4}$. RF increases as the operating pressure

3 increases due to the increased GSCHS. SF increases as the operating pressure increases,

4 and reaches the peak at $3 \mathrm{Mpa}$ then shows a tendency of decrease when the pressure

5 increases further. The decrease in усн4 leads to the increase in SF while the decrease in

$6 \mathrm{XCH4}$ leads to the decrease in SF. When operating pressure is higher than a specific value,

7 the increase in operating pressure has a greater effect on the decrease in хсн4 than on

8 the decrease in усн4 which leads to the decrease in SF.

As it can be seen from Fig. 11b, the experimental and modeling results are pretty close. The ARD, ARV and MRD are 2.65\%, 0.0195 and 9.28\%, respectively. The GF is 0.73 for $\mathrm{XCH}_{4}, 0.97$ for $\mathrm{yCH} 4$ and 0.99 for GSCHS. High operating pressure leads to formation of more hydrate and high $\mathrm{CH}_{4}$ recovery. On the other hand, it also leads to decreased хсн4 and may cause decrease in SF due to the decrease in the selectivity of $\mathrm{CH}_{4}$ capture in hydrate. In addition, high operating pressure may lead to higher energy consumption and higher capital and operation costs. The optimal operating pressure needs careful examination of the whole process from different aspects. 2.5 MPa was chosen as the operating pressure to ensure the increase in the хсH4 meets the demand of the three- stage separation.

\subsubsection{Effect of CSG concentration on the separation} performance

The effect of $\mathrm{CH}_{4}$ content on the separation was examined at $281.15 \mathrm{~K}$ with $\mathrm{CL}$ at $30 \mathrm{NL} / \mathrm{L}$ and $0.901 \mathrm{~mol} \% \mathrm{TBAB}$ solution. The operating pressure was also changed in some experiments to better understand the separation performance. The experimental 
results and corresponding modeling results are compared in Table 8.

As shown in Table 8, the composition of the model CSG in E2 $\left(50.9 \mathrm{~mol} \% \mathrm{CH}_{4}\right)$ is the same as that of the dissociated gas in E1, and the composition of the model CSG in $\mathrm{E} 3, \mathrm{E} 4, \mathrm{E} 5$ and $\mathrm{E} 6\left(65.9 \mathrm{~mol} \% \mathrm{CH}_{4}\right)$ is very close to that of the dissociated gas in $\mathrm{E} 2$ (65.8 $\left.\mathrm{mol}_{\%} \mathrm{CH} 4\right)$. The results experimental confirm that the concentration of the $\mathrm{CH}_{4}$ can be enhanced from $34.6 \mathrm{~mol} \%$ to $81.3( \pm 0.1) \mathrm{mol} \%$ after three stage separation. The composition of the model CSG in E7 $(23.7 \mathrm{~mol} \%)$ is the same as that of the residual gas in E1 and the composition of the model CSG in E8(13.3 mol\%) is equal to that of the residual gas in E7. So, the concentration of $\mathrm{CH}_{4}$ of a model CSG containing 34.6 mol\% $\mathrm{CH}_{4}$ can be reduced to $7.2( \pm 0.1) \mathrm{mol} \%$ in the residual gas after three stage separation. It is noted that a higher $\mathrm{CH}_{4}$ concentration is obtained in the dissociated gas when the operating pressure is lower, while a higher operating pressure was chosen in experiments $\mathrm{E} 7$ and $\mathrm{E} 8$ to maximize $\mathrm{CH}_{4}$ recovery. Table 8 also shows that the predicted results show good agreement with the experimental values in each experiment.

Overall, the ARD of all of the modeling data with the experimental data is $2.83 \%$; the MRD is $11.20 \%$, and ARV is 0.1044 . They show an improvement from those in previous researches. In previous researches, ${ }^{[49,50]}$ trial-and-error method is used to predict the performance of hydrate based separation. The relationship between the final compositions of residual gas and dissociated gas are directly determined by Langmuir adsorption theory (Eqs. 16a and 16b). In real hydrate formation process, the existing hydrate is covered by new formed hydrate during hydrate forming, so the gas molecules captured by hydrate is encapsulated. As a result, the hydrate cavities inner of a hydrate grain can neither release nor intake gas species during the following separation period. In this work, the equilibrium of Langmuir adsorption is assumed between the new formed hydrate and the gas phase at every moment during the hydrate formation, and 
the part of hydrate does not change its composition during the extended period of separation. Thus, the composition of gas phase changes continuously and so does the hydrate formed. When the separation reaches thermodynamic equilibrium, the final compositions of the residual gas and the dissociated gas are not in equilibrium following the Langmuir adsorption theory. This may be why in Ref. ${ }^{[49]}$, the ARD of residual gas composition is $10 \%$ and that of dissociated gas is even higher. In addition, the larger the amount of hydrate forms the larger the change of gas phase composition is, and the larger the error can be in the prediction of the dissociated gas composition. In Ref. ${ }^{[50]}$, the convergence condition is the equilibrium among L-V-H three-phases as given in Ref. ${ }^{[83]}$ Since the equilibrium condition is used for hydrate dissociation near critical point of the hydrate formation, its scope of application is limited near the critical point of the hydrate formation. In this work, the operating conditions are not subject to the limitation because it considers the separation as a dynamic process, and the change of the chemical potential is considered as the driving force for hydrate formation.

\subsection{Prediction of the separation performance by}

\section{multistage separation modelling}

Based on the single stage separation model, a multistage separation model was established to predict the separation performance. Based on the previous experimental results, lower operating pressure, higher temperature and lower initial concentration of the TBAB in the solution lead to a greater increment of $\mathbf{x C H 4}_{\mathbf{4}}$, but a smaller decrement

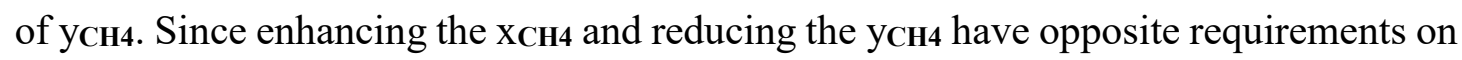
the initial concentration of TBAB in solution, the concentrations of TBAB in solutions in all of stages were set at $0.901 \mathrm{~mol} \%$ so that the system only needed one liquid storage 
tank. The initial gas/liquid ratio was set at $30 \mathrm{NL} / \mathrm{L}$, and the volume of the model CSG flowing into the multistage separation system was set at $10 \mathrm{NL}$.

First, the operating temperatures of all operating units were set at $281.15 \mathrm{~K}$ in order to investigate the effect of the operating pressures in five operating units on the multistage separation. Several combinations of the operating pressure were tried. The predicted separation performance is presented in Table 9. When the operating pressures of all operating units are the same, the recycle ratio of gas is normally smaller than when the operating pressures are different, but $\mathrm{CH}_{4}$ is not efficiently concentrated. When the pressures of all operating units are the same and decreased from $3.5 \mathrm{MPa}$ to 2.5 $\mathrm{MPa}$, the SF decreases from 52.4 to 22.9 , and the RF decreases from $92.8 \mathrm{~mol} \%$ to $67.8 \mathrm{~mol} \%$. The $\mathrm{CH}_{4}$ concentration in the final dissociated gas increases from $70.1 \mathrm{~mol} \%$ to $81.0 \mathrm{~mol} \%$, and that in the final residual gas increases from $4.5 \mathrm{~mol} \%$ to $15.7 \mathrm{~mol} \%$. To enhance хсн4 needs low operating pressure while to reduce усн4 needs high operating pressure. In order to enhance the separation efficiency, operating pressures of operating units S2_1 and S3_1 were increased and that of S3_2 was reduced. Based on the separation efficiency (high SF), the concentration demand $\left(\mathrm{CH}_{4}\right.$ content $\left.>80 \mathrm{~mol} \%\right)$ and the recovery rate (high RF), it can be seen that best separation results was achieved when S3_2 was set at $1 \mathrm{MPa}$ and the other operating units were set at 3.5 MPa. For this reason, the S3_2 was set at $1 \mathrm{MPa}$ and the other operating unit were set at $3.5 \mathrm{MPa}$ in the following modeling to determine the operating temperature.

Several combinations of the operating temperature were tried, and the results are presented in Table 10. When the temperatures of all operating units are the same, the SF and RF increase with the decrease of the operating temperatures, but the concentrations of $\mathrm{CH}_{4}$ decrease at the same time. It can be seen that the $\mathrm{SF}$ and $\mathrm{RF}$ under different combinations of the operating temperatures have not much difference. 
1 In order to avoid the energy consumption on warming and cooling, the operating temperatures of all separation stages were set at $280.15 \mathrm{~K}$. The major operating conditions of the multistage separation system are summarized in Table 11.

It can be seen from Table 11 that the volume of the gas flowing into unit S1 (33.6 $\mathrm{NL})$ is more than three times the volume of the model CSG (10 NL) which is caused by the gas streams returned from S2_1 (9.9 NL) and S2_2 (13.7 NL). The volume of the gas returned from S2_2 alone is larger than that of the model CSG. The concentration of $\mathrm{CH}_{4}$ in the gas flowing into unit $\mathrm{S} 1(38.6 \mathrm{~mol} \%)$ is higher than that in model CSG (34.6 mol\%). This is also caused by the gas streams which flow back from the S2_1(35.4 mol\%) and S2_2 (43.9 mol\%). The amount of the gas flowing into S2_2 $(31.5 \mathrm{NL})$ is as large as that of $\mathrm{S} 1(31.6 \mathrm{NL})$. Because the reflux ratio of the S3_2 is as high as $78.4 \%$, only $21.6 \%$ of the inlet gas is output as dissociated gas satisfying the $\mathrm{CH}_{4}$ content requirement. In order to achieve a high content $\mathrm{CH}_{4}$, the operating pressure of the S3_2 was set very low (1 MPa). This means that the SF of S3_2 (2.35) is the lowest while its reflux ratio (78.4\%) is the highest among all the operating units. After multistage separation, the concentration of $\mathrm{CH}_{4}$ is enhanced to $81.0 \mathrm{~mol} \%$ in the final dissociated gas and the $\mathrm{CH}_{4}$ content in the final residual gas is reduced to $5.5 \mathrm{~mol} \%$. The recovery rate of $\mathrm{CH}_{4}$ is $90.1 \%$ and the separation factor is 73.0 .1 .

\section{Conclusions}

The separation of $\mathrm{CH}_{4}$ from $\mathrm{CSG}$ was investigated experimentally, and a model was established to predict the CSG separation performance by hydrate formation using TBAB aqueous solution. The effects of different influential factors on the separation were examined. Low operating temperature, high operating pressure and high concentration of $\mathrm{TBAB}$ in solution favors high $\mathrm{CH}_{4}$ recovery rate, but results in low 
$1 \mathrm{CH}_{4}$ capture selectivity in the hydrate slurry. High CSG to liquid volumetric ratio is

2 helpful to increasing the $\mathrm{CH}_{4}$ concentration in the dissociated gas, but reduces the

3 recovery of $\mathrm{CH}_{4}$, leaving residual gas with a high $\mathrm{CH}_{4}$ content. The results show that a

4 single stage separation process is incapable of separating $\mathrm{CH}_{4}$ from $\mathrm{CSG}$ with

5 satisfactory $\mathrm{CH}_{4}$ concentration and recovery, and a multistage separation process is necessary. Experimental simulation of a three-stage separation shows that $\mathrm{CH}_{4}$ can be concentrated to $81.3 \mathrm{~mol} \%$ in the final dissociated gas, and its content in the residual gas can be reduced to $7.12 \mathrm{~mol} \%$.

The established hydrate separation model was used to simulate the experimental data, and the predicted results match the experimental results satisfactorily. The average relative deviation (ARD) of all the results in this study is $2.83 \%$, with the maximum relative deviation (MRD) being $11.20 \%$, and the average relative variance (ARV) being 0.1044 .

The modeling method was applied to predict the performance of multistage separation process. In a three-stage separation model to separate a model CSG containing $34.6 \mathrm{~mol}^{\%} \mathrm{CH}_{4}$, the concentration of the $\mathrm{CH}_{4}$ is enhanced to $81.0 \mathrm{~mol} \%$ in the final dissociated gas and is reduced to $5.5 \mathrm{~mol} \%$ in the final residual gas. The recovery rate of $\mathrm{CH}_{4}$ is $90.1 \%$ and the separation factor is 73.0 .

\section{Acknowledgement}

This work was supported by Research Foundation of China University of Petroleum-Beijing at Karamay (RCYJ2017A-02-001, RCYJ2017A-03-001), Science Foundation of China University of Petroleum, Beijing (YJRC-2013-09), and National Natural Science Foundation of China (21306226), which are greatly acknowledged. 
1 Cincotta and Mr. Hemeng $\mathrm{Bi}$ in the final language editing of this paper.

\section{Nomenclature}

\section{Abbreviation}

\begin{tabular}{|c|c|c|}
\hline 4 & ARD & Average relative deviation \\
\hline 5 & ARV & Average relative variance \\
\hline 6 & CSG & Coal seam gas \\
\hline 7 & GF & Goodness of fit \\
\hline 8 & GSCHS & Gas storage capacity of the hydrate slurry \\
\hline 9 & $\mathrm{CL}$ & Volumetric CSG/liquid ratio (ratio of the model CSG volume at \\
\hline 10 & & $273.15 \mathrm{~K}, 101325 \mathrm{~Pa}$ to the volume of $\mathrm{TBAB}$ solution at the \\
\hline 11 & & beginning of experiment) \\
\hline 12 & MRD & Maximum relative deviation \\
\hline 13 & Rec & Recycle ratio \\
\hline 14 & Ref & Reflex ratio \\
\hline 15 & $\mathrm{RF}$ & Recovery fraction \\
\hline 16 & SF & Separation factor \\
\hline 17 & TBAB & Tetra butyl ammonium bromide \\
\hline
\end{tabular}

18 Symbols

$19 \lambda_{1}$

20

$21 \quad \lambda_{2}$
Ratio of the number of linked cavities to water molecules in a basic hydrate unit

Ratio of the number of TBAB molecules to water molecules in a 
basic hydrate unit

The fraction of the linked cavities filled by gas molecules

Chemical potential of basic TBAB semi-clathrate hydrate

Chemical potential of TBAB under standard condition $(273.15 \mathrm{~K}$,

$101325 \mathrm{~Pa})$

Chemical potential of water

Chemical potential of TBAB

Chemical potential of the final hydrate

Kinematic viscosity of TBAB solution

Interfacial tension between TBAB solution and CSG

Activity coefficient

The difference between final chemical potential and initial chemical potential

Density of TBAB solution

Structural parameter, $\alpha=\lambda_{1} / \lambda_{2}$

Structural parameter, $\beta=3.5 \mathrm{~K} / \mathrm{bar}$ for type B TBAB hydrate and

$2.8 \mathrm{~K} /$ bar for type A

Activity of the water in the TBAB solution

Corrected coefficients between $\mathrm{CH}_{4}$ and $\mathrm{TBAB}$

Corrected coefficients between $\mathrm{N}_{2}$ and TBAB

Antoine constants for calculating $\mathrm{f}_{\mathrm{T}}^{0}(\mathrm{~T})$

Antoine constants for calculating $\mathrm{f}_{\mathrm{T}}^{0}(\mathrm{~T})$ 


\begin{tabular}{|c|c|c|}
\hline 1 & $\mathrm{C}^{\prime}$ & Antoine constants for calculating $\mathrm{f}_{\mathrm{T}}^{0}(\mathrm{~T})$ \\
\hline 2 & $\mathrm{C}$ & Langmuir constant \\
\hline 3 & $\mathrm{f}^{0}$ & Fugacity of TBAB in the unfilled basic hydrate \\
\hline 4 & $\mathrm{f}$ & Fugacity of gas species and TBAB \\
\hline 5 & g & Empirical constants for calculating $\rho_{\text {sol }}$ \\
\hline 6 & $\mathrm{~h}$ & The change of the moles of substance during $\Delta t$ \\
\hline 7 & $\mathrm{Hg}$ & The moles of gas in the hydrate phase \\
\hline 8 & $\mathrm{k}$ & Parameter of the hydrate forming rate \\
\hline 9 & M & Molecular weight \\
\hline 10 & $\mathrm{~m}$ & Mass \\
\hline 11 & $\mathrm{~N}$ & Moles of substances \\
\hline 12 & $\mathrm{n}$ & Number of experimental data points \\
\hline 13 & $\mathrm{Ng}$ & The moles of gas in the gas phase in the crystallizer \\
\hline 14 & $\mathrm{O}$ & Empirical constants for calculating $\rho_{\text {sol }}$ \\
\hline 15 & $\mathrm{P}$ & Pressure \\
\hline 16 & $\mathrm{P}_{\mathrm{TBAB}}^{\text {sat }}$ & Saturated vapor pressure of TBAB \\
\hline 17 & q & Empirical constants for calculating $\rho_{\text {sol }}$ \\
\hline 18 & $\mathrm{r}$ & Gas capture rate \\
\hline 19 & ratio & Ratio of gas volume to TBAB solution volume under $273.15 \mathrm{~K}$, \\
\hline 20 & & $101325 \mathrm{~Pa}$ \\
\hline 21 & $\mathrm{~s}$ & Empirical constants for calculating $\rho_{\text {sol }}$ \\
\hline 22 & teq & Time when the separation reaches steady \\
\hline 23 & V & Volume \\
\hline
\end{tabular}


$1 \quad \mathrm{v}_{\mathrm{TBAB}}^{\mathrm{L}}$

2 WTBAB

$3 x$

4 ХTВAB

$5 \mathrm{X}^{\prime}$

$6 \quad \mathrm{y}$

$7 \mathrm{Y}^{\prime}$

$8 \quad$ Z

9 Z

$10 \quad \mathrm{zZ}$

11

12 Subscript

13 "A" "B"

14 back

15 cal

$16 \mathrm{~d}$

$17 \exp$

$18 \quad \mathrm{i}$

19 in

$20 \mathrm{j}$

$21 \mathrm{jjj}$
Molar volume of TBAB in the solution

Mass fraction of TBAB in the solution.

Concentration of gas species in the dissociated gas

Mole fraction of the TBAB in the liquid phase

Antoine constant for calculating Langmuir constant

Concentration of gas species in the residual gas

Antoine constant for calculating Langmuir constant

Antoine constant for calculating Langmuir constant

Compressibility factor

Concentration of gas species in feed gas of different operating units in multistage separation
The separation stage “A”, No. "B” operating unit

The gas flowing out of the operating unit to the above stage

Calculation result

Dissociated gas

Experimental result

Number of iterations in multistage separation

The gas flowing into the operating unit

Number of iterations in single stage separation

Sequence number for the repeated experiments 
$1 \quad \mathrm{r}$

2 sol

3 stp
Residual gas

TBAB solution

Under 273.15 K, $101325 \mathrm{~Pa}$

\section{REFERENCES}

5 [1] Sarhosis V, Jaya AA, Thomas HR. Economic modelling for coal bed methane

$6 \quad$ production and electricity generation from deep virgin coal seams. Energy 2016; $7 \quad 107: 580-594$.

8 [2] Zhong DL, Ding K, Lu YY, Yan J, Zhao WL. Methane recovery from coal mine gas using hydrate formation in water-in-oil emulsions. Appl Energy 2016; 162: $1619-1626$.

[3] Yang ZQ, Grace JR, Lim CJ, Zhang L. Combustion of low-concentration coal bed Methane in a fluidized bed. Energy Fuel 2011; 5: 975-980.

[4] Huang Y, Zheng QP, Fan N, Aminian K. Optimal scheduling for enhanced coal bed methane production through $\mathrm{CO}_{2}$ injection. Appl Energy 2014; 113: 1475-1483.

[5] Su S, Beath A, Guo H, Mallett C. An assessment of mine methane mitigation and utilization technologies. Prog Energ Combust 2005; 31: 123-170.

[6] Peng XQ, Zhang BS, Chu WT, Liu LL. Benefit assessment on CSG development in China. Nat Gas Ind 2008; 28: 124-126.

[7] Yang M. Climate change and energy policies, coal and coalmine methane in China. Energ Policy 2009; 37: 2858-2869.

[8] Berntsen TK, Fuglestvedt JS, Joshi MM, ShineKP, Stuber N, Ponater M, Sausen R, Hauglustaine DA, Li L. Climate response to regional emissions of ozone precursors; sensitivities and warming potentials. Tellus B 2005; 4: 283-304. 
1 [9] Cai J, Xu CG, Xia ZM, Chen ZY, Li XS. Hydrate-based methane separation from coal mine methane gas mixture by bubbling using the scale-up equipment. Applied Energy 2017.

[10]Olajossy A, Gawdzik A, Budner Z, Dula J. Methane separation from coal mine methane gas by vacuum pressure swing adsorption. Chem Eng Res Des 2003; 81: $474-482$.

[11]Zhong D, Englezos P. Methane separation from coal mine methane gas by tetra-nbutyl ammonium bromide semiclathrate hydrate formation. Energy Fuel 2012; 26(4): 2098-2106.

[12]Zhong DL, Daraboina N, Englezos P. Coal Mine Methane Gas Recovery by Hydrate Formation in a Fixed Bed of Silica Sand Particles. Energy Fuel 2013; 27: $4581-4588$.

[13]Wang YW, Du M, Guo XQ, Sun Q, Liu AX, Chen B, Chen GJ, Sun CY, Yang LY. Experiments and simulations for continuous recovery of methane from coal seam gas (CSG) utilizing hydrate formation. Energy 2017; 129: 28-41.

[14] Sloan ED, Koh CA. Clathrate hydrates of natural gases. 3rd ed. Boca Raton: CRC/Taylor \& Francis; 2008.

[15] Sloan ED. Fundamental principles and applications of natural gas hydrates. Nature 2003; 426: 353-363.

[16]Lee H, Lee JW, Kim DY, Park J, Seo YT, Zeng H, Moudrakovski IL, Ratcliffe CI, Ripmeester JA. Tuning clathrate hydrates for hydrogen storage. Nature 2005; 434: 743-746.

[17]Pivezhani F, Roosta $\mathrm{H}$, Dashti A, Mazloumi SH. Investigation of $\mathrm{CO}_{2}$ hydrate formation conditions for determining the optimum $\mathrm{CO}_{2}$ storage rate and energy: Modeling and experimental study. Energy 2016; 113: 215-226. 
1 [18]Lee Y, Kim Y, Lee J, Lee H, Seo Y. $\mathrm{CH}_{4}$ recovery and $\mathrm{CO}_{2}$ sequestration using flue gas in natural gas hydrates as revealed by a micro-differential scanning calorimeter. Appl Energy 2015; 150: 120-127.

[19]Babu P, Linga P, Kumar R, Englezos P. A review of the hydrate based gas separation (HBGS) process for carbon dioxide precombustion capture. Energy 2015; 85: 261279.

[20] Wang Y, Lang X, Fan SS. Hydrate capture $\mathrm{CO}_{2}$ from shifted synthesis gas, flue gas and sour natural gas or biogas. J Energy Chem 2013; 22: 39-47.

[21]Chong ZR, Yang SHB, Babu P, Linga P, Li XS. Review of natural gas hydrates as an energy resource: Prospects and challenges. Appl Energy 2016; 106: 1633-1652.

[22]Feng JC, Wang Y, Li XS. Energy and entropy analyses of hydrate dissociation in different scales of hydrate simulator. Energy 2016; 102: 176-186.

[23]Feng JC, Wang Y, Li XS. Entropy generation analysis of hydrate dissociation by depressurization with horizontal well in different scales of hydrate reservoirs. Energy 2017; 125: 62-71.

[24]Wang F, Fu SF, Guo G, Jia ZZ, Luo SJ, Guo RB. Experimental study on hydratebased $\mathrm{CO}_{2}$ removal from $\mathrm{CH}_{4} / \mathrm{CO}_{2}$ mixture. Energy 2016; 104: 76-84.

[25] Yang M, Jing W, Zhao J, Ling Z, Song YC. Promotion of hydrate-based $\mathrm{CO}_{2}$ capture from flue gas by additive mixtures (THF (tetrahydrofuran)+ TBAB (tetran-butyl ammonium bromide)). Energy 2016; 106: 546-553.

[26]Veluswamy HP, Kumar A, Premasinghe K, Linga P. Effect of guest gas on the mixed tetrahydrofuran hydrate kinetics in a quiescent system. Applied Energy 2017.

[27] Veluswamy HP, Ang WJ, Zhao D, Linga P. Influence of cationic and non-ionic surfactants on the kinetics of mixed hydrogen/tetrahydrofuran hydrates. Chem Eng Sci 2015; 132: 186-199. 
1 [28]Kim S, Lee SH, Kang YT. Characteristics of $\mathrm{CO}_{2}$ hydrate formation/dissociation in $\mathrm{H}_{2} \mathrm{O}+\mathrm{THF}$ aqueous solution and estimation of $\mathrm{CO}_{2}$ emission reduction by district cooling application. Energy 2017; 120: 362-373.

[29] Wang X, Dennis M. An experimental study on the formation behavior of single and binary hydrates of TBAB, TBAF and TBPB for cold storage air conditioning applications. Chem Eng Sci 2015; 137: 938-946.

[30]Renault-Crispo JS, Coulombe S, Servio P. Kinetics of carbon dioxide gas hydrates with tetrabutylammonium bromide and functionalized multi-walled carbon nanotube. Energy 2017; 128: 414-420.

[31]Cai J, Xu CG, Lin FH, Yu HZ, Li XS. A novel method for evaluating effects of promoters on hydrate formation. Energy 2016; 102: 567-575.

[32] Kim S, Choi SD, Seo Y. $\mathrm{CO}_{2}$ capture from flue gas using clathrate formation in the presence of thermodynamic promoters. Energy 2017; 118: 950-956.

[33] Veluswamy HP, Chen JY, Linga P. Surfactant effect on the kinetics of mixed hydrogen/propane hydrate formation for hydrogen storage as clathrates. Chem Eng Sci 2015; 126: 488-499.

[34] Wang F, Jia ZZ, Luo SJ, Fu SF, Wang L, Shi XS, Wang CS, Guo RB. Effects of different anionic surfactants on methane hydrate formation. Chem Eng Sci 2015; 137: 896-903.

[35] Veluswamy HP, Kumar A, Kumar R, Linga P. An innovative approach to enhance methane hydrate formation kinetics with leucine for energy storage application. Appl Energy 2017;188: 190-199.

[36]Zhou MZ, Xia GD, Li J, Chai L, Zhou L. Analysis of factors influencing thermal conductivity and viscosity in different kinds of surfactant solutions. Experimental Thermal and Fluid Science 2012; 36: 22-29. 
1 [37]Martinov M, Gancel F, Jacques P, Nikov I, Vlaev S. Surfactant effects on aeration performance of stirred tank reactors. Chemical engineering \& technology 2008; 31(10): 1494-1500.

[38]Ding YL, Xu CG, Yu YS, Li XS. Methane recovery from natural gas hydrate with simulated IGCC syngas. Energy 2017; 120: 192-198.

[39]Xia ZM, Li XS, Chen ZY, Li G, Yan KF, Xu CG, Lv QN, Cai J. Hydrate-based CO2 capture and $\mathrm{CH}_{4}$ purification from simulated biogas with synergic additives based on gas solvent. Appl Energy 2016; 162: 1153-1159.

[40]Zheng J, Zhang P, Linga P. Semiclathrate hydrate process for pre-combustion capture of $\mathrm{CO}_{2}$ at near ambient temperatures. Applied Energy 2017; 194: 267-278.

[41] Xu CG, Zhang SH, Cai J, Chen ZY, Li XS. CO2 (carbon dioxide) separation from $\mathrm{CO}_{2}-\mathrm{H}_{2}$ (hydrogen) gas mixtures by gas hydrates in TBAB (tetra-n-187 butyl ammonium bromide) solution and Raman spectroscopic analysis. Energy 2013; 59: $719-725$.

[42] Hashimoto H, Yamaguchi T, Kinoshita T, Muromachi S. Gas separation of flue gas by tetra-n-butylammonium bromide hydrates under moderate pressure conditions. Energy 2017; 129: 292-298.

[43] Song WJ, Xiao R, Huang C, He SH, Dong KJ, Feng ZP. Experimental investigation on TBAB clathrate hydrate slurry flows in a horizontal tube: Forced convective heat transfer behaviors. Int J Refrig 2009; 32: 1801-1807.

[44]Chen GJ, Guo TM. A new approach to gas hydrate modelling. Chem Eng J 1998; 71: $145-151$.

[45]Chen GJ, Guo TM. Thermodynamic modeling of hydrate formation based on new concepts. Fluid Phase Equilib 1996; 122: 43-65.

[46]Zhou H, de Sera IE, Infante Ferreira CA. Modelling and experimental validation 
of a fluidized bed based $\mathrm{CO}_{2}$ hydrate cold storage system. Appl Energy 2015; 15: $433-445$.

[47]Liao ZX, Guo XQ, Li Q, Sun Q, Li J, Yang LY, Liu AX, Chen GJ, Zuo JY. Experimental and modeling study on the phase equilibria for hydrates of gas mixtures in TBAB solution. Chem Eng Sci 2015; 137: 656-664.

[48]Liao ZX, Guo XQ, Zhao YY, Wang YW, Sun Q, Liu AX, Sun CY, Chen GJ. Experimental and modeling study on phase equilibria of semiclathrate hydrates of tetra-n-butyl ammonium bromide $+\mathrm{CH}_{4}, \mathrm{CO}_{2}, \mathrm{~N}_{2}$, or Gas Mixtures. Ind Eng Chem Res 2013; 52: 18440-18446.

[49] Ma QL, Qi LJ, Chen GJ, Sun CY. Modeling study on phase equilibria of emiclathrate hydrates of pure gases and gas mixtures in aqueous solutions of TBAB and TBAF. Fluid Phase Equilib 2016; 430: 178-187.

[50]Fukumoto A, Paulo L, Silva S, Paricaud P, Dalmazzone D, Furst W. Modeling of the dissociation conditions of $\mathrm{H}_{2}+\mathrm{CO}_{2}$ semiclathrate hydrate formed with TBAB, TBAC, TBAF, TBPB, and $\mathrm{TBNO}_{3}$ salts. Application to $\mathrm{CO}_{2}$ capture from syngas. Int J Hydrogen Energy 2015; 40: 9254 - 9266.

[51]Tumba K, Mohammadi AH, Naidoo, Ramjugernath D. Assessing hydrate formation as a separation process for mixtures of close-boiling point compounds: A modelling study. J Nat Gas Sci Eng 2016; 35: 1405-1415.

[52]Zhong DL, Lu YY, Sun DJ, Zhao WL, Li Z. Performance evaluation of methane separation from coal mine gas by gas hydrate formation in a stirred reactor and in a fixed bed of silica sand. Fuel 2015; 143: 586-594.

[53]Kang SP, Lee H, Lee CS, Sung WM. Hydrate phase equilibria of the guest mixtures containing $\mathrm{CO}_{2}, \mathrm{~N}_{2}$ and tetrahydrofuran. Fluid Phase Equilibria 2001; 185(1): 101109. 
1 [54]Qin HB, Sun CY, Sun ZF, Liu B, Chen GJ. Relationship between the interfacial tension and inhibition performance of hydrate inhibitors. Chemical Engineering Science 2016; 148: 182-189.

[55] Sun CY, Chen GJ, Yang LY. Interfacial tension of methane+ water with surfactant near the hydrate formation conditions. Journal of Chemical \& Engineering Data 2004; 49(4): 1023-1025.

[56]Patel NC, Teja AS. A new cubic equation of state for fluids and fluid mixtures. Chem Eng Sci 1982; 37: 463-473.

[57]Li XS, Xu CG, Chen Y, Wu HJ. Tetra-n-butyl ammonium bromide semi-clathrate hydrate process for post-combustion capture of carbon dioxide in the presence of dodecyl trimethyl ammonium chloride. Energy 2010; 35: 3902-3908.

[58] Seo Y, Kang SP. Enhancing $\mathrm{CO}_{2}$ separation for pre-combustion capture with hydrate formation in silica gel pore structure. Chem Eng J 2010; 161: 308-312.

[59]Xia ZM, Li XS, Chen ZY, Yan KF, Xu CG, Cai J. Hydrate-based hydrogen purification from simulated syngas with synergic additives. Int J Hydrogen Energy 2016; 41: 2649-2659.

[60]Lee HJ, Lee JD, Linga P, Englezos P, Kim YS, Lee MS, Kim YD. Gas hydrate formation process for pre-combustion capture of carbon dioxide. Energy 2010; 35: 2729-33.

[61]Hu J, Li SJ, Wang YH, Lang XM, Li QP, Fan SS. Kinetic hydrate inhibitor performance of new copolymer poly(N-vinyl-2-pyrrolidone-co-2-vinyl pyridine)s with TBAB. J Nat Gas Chem 2012; 21: 126-131.

[62] Nguyen NN, Nguyen AV, Nguyen KT, Rintoul L, Dang LX. Unexpected inhibition of $\mathrm{CO}_{2}$ gas hydrate formation in dilute $\mathrm{TBAB}$ solutions and the critical role of interfacial water structure. Fuel 2016; 185: 517-523. 
1 [63] Wang YW, Deng Y, Guo XQ, Sun Q, Liu AX, Chen GJ, Sun CY, Yang LY. The use of hydrate formation for the continuous recovery of ethylene and hydrogen from fluid catalytic cracking dry gas. Sep Purif Technol 2017; 187: 162-172.

[64]Long JP, Sloan Jr ED, Quantized water clusters around apolar Molecules. Mol Simul 1993; 11: 145-161.

[65] Yusuke J, Masato K, Jiro N. Phase Equilibrium condition for clathrate hydrates of tetra-n-butyl ammonium bromide (TBAB) and xenon. J Chem Eng Data 2012; 57 : 1829-1833.

[66]Ohmura R, Takeya S, Uchida T, Ebinuma T. Clathrate hydrate formed with methane and 2-propanol: Confirmation of structure II hydrate formation. Ind Eng Chem Res 2004; 43: 4964-4966.

[67]Chen GJ, Sun CY, Ma QL. Science and technology of gas hydrate, 1st ed., Chemical Industry Press, Beijing, 2008.

[68]Belandria V, Eslamimanesh A, Mohammadi AH, Theveneau P, Legendre H, Richon D. Compositional analysis and hydrate dissociation conditions measurements for carbon dioxide + methane +water system. Ind Eng Chem Res 2011; 50: 5783-5794.

[69]Belandria V, Eslamimanesh A, Mohammadi A H, Richon D. Gas hydrate formation in carbon dioxide + nitrogen + water system: Compositional analysis of equilibrium phases. Ind Eng Chem Res 2011; 50(8): 4722-4730.

[70]Poling BE, Prausnitz JM, O’Connell JP. The Properties of Gases and Liquids. McGraw-Hill, New York, 2001.

[71]Lindenbaum S, Boyd GE. Osmotic and activity coefficients for the symmetrical tetra alkyl ammonium halides in aqueous solution at $25^{\circ} \mathrm{C}$. J Phys Chem 1964; 68: 911-917.

[72]Amado GE, Blanco LH. Isopiestic determination of the osmotic and activity 
coefficients of dilute aqueous solutions of symmetrical and unsymmetrical quaternary ammonium bromides with a new isopiestic cell at $298.15 \mathrm{~K}$. Fluid Phase Equilib 2005; 233: 230-233.

[73] Söhnel O, Novotny P. Densities of aqueous solutions of inorganic substances. Elsevier Science Pub.Co: Amsterdam, 1985.

[74]Belandria V, Mohammadi AH, Richon D. Volumetric properties of the (tetrahydrofuran + water) and (tetra-n-butyl ammonium bromide + water) systems: experimental measurements and correlations. J Chem Thermodyn 2009; 41: $1382-1386$.

[75]Chen LF, Soriano AN, Li MH. Vapor pressures and densities of the mixed-solvent desiccants (glycols + water + salts). J Chem Thermodyn 2009; 41: 724-730.

[76] Wang YW, Zhang JH, Guo XQ, Chen B, Sun Q, Liu AX, Sun CY, Chen GJ, Yang LY. Experiments and modeling for recovery of hydrogen and ethylene from fluid catalytic cracking (FCC) dry gas utilizing hydrate formation. Fuel 2017; 209: 473489.

[77]Akatsu S, Tomita S, Mori YH, Ohmura R. Thermodynamic simulations of hydratebased removal of carbon dioxide and hydrogen sulfide from low-quality natural gas. Ind Eng Chem Res 2013; 52(43): 15165-15176.

[78] Yao YY, Chen CG, Chai CJ. Chemical Engineering, 3 rd ed., Tianjin university press, Tianjin, 2010.

[79] Sinha B, Sarkar BK, Roy MN. Apparent molar volumes and viscosity Bcoefficients of nicotinamide in aqueous tetrabutylammonium bromide solutions at $\mathrm{T}=(298.15,308.15$, and 318.15) K. The Journal of Chemical Thermodynamics 2008; 40(3): 394-400.

[80]Akiba $\mathrm{H}$, Ohmura R. Interfacial tension between $\left(\mathrm{CO}_{2}+\mathrm{N}_{2}\right)$ gas and 
tetrabutylammonium bromide aqueous solution. The Journal of Chemical Thermodynamics 2016; 97: 83-87.

3 [81] Bi Y, Chen J, Miao Z. Thermodynamic optimization for dissociation process of gas $4 \quad$ hydrates. Energy 2016; 106: 270-276.

5 [82]ZareNezhad B, Mottahedin M, Varaminian F. A new approach for determination of 6 single component gas hydrate formation kinetics in the absence or presence of kinetic promoters. Chemical Engineering Science 2015; 137: 447-457.

[83]Paricaud P. Modeling the dissociation conditions of salt hydrates and gas semiclathrate hydrates: application to lithium bromide, hydrogen iodide, and tetran-butylammonium bromide+ carbon dioxide systems. The Journal of Physical Chemistry B 2010; 115(2): 288-299. 
Table 1 The operating experimental conditions of present study in comparison with those in literatures

\begin{tabular}{|c|c|c|c|c|c|}
\hline Study & $\begin{array}{c}\text { Feed gas } \mathrm{CH}_{4} / \mathrm{N}_{2} \\
\text { mol ratio }\end{array}$ & $\begin{array}{l}\text { Temperature } \\
\text { (constant, K) }\end{array}$ & Pressure (MPa) & Promoter & Reactor \\
\hline Cai et al. [9] & $50.0 / 50.0$ & 277.15 & Constant at 1.5 & $1 \mathrm{~mol} \% \mathrm{THF}$ & $\begin{array}{l}\text { Bubble column (Semi- } \\
\text { batch) }\end{array}$ \\
\hline \multirow{2}{*}{$\begin{array}{l}\text { Zhong et } \\
\text { al. [11] }\end{array}$} & \multirow{2}{*}{$30.0 / 70.0$} & $\begin{array}{c}276.15,277.15 \\
280.15\end{array}$ & $\begin{array}{c}\text { Constant at } 4.2,3.9 \text { and } \\
3.8\end{array}$ & $\begin{array}{c}0.17 \mathrm{~mol} \%, 0.29 \mathrm{~mol} \% \text { and } 0.62 \mathrm{~mol} \% \\
\text { TBAB }\end{array}$ & Semi-batch \\
\hline & & 277.15 & Initial (maximum) 3.9 & $0.29 \mathrm{~mol} \% \mathrm{TBAB}$ & Batch (fixed volume) \\
\hline \multirow{2}{*}{$\begin{array}{c}\text { Zhong et } \\
\text { al. }{ }^{[12]}\end{array}$} & \multirow{2}{*}{$30.0 / 70.0$} & 273.65276 .05 & $\begin{array}{l}\text { Initial (maximum) } 9,10, \\
3.4\end{array}$ & $1 \mathrm{~mol} \% \mathrm{THF}$ & \multirow{2}{*}{ Batch (fixed volume) } \\
\hline & & 276.05 & Initial (maximum) 3.4 & $1 \mathrm{~mol} \% \mathrm{THF}+$ Silica sand particles & \\
\hline Wang et al. & $34.6 / 65.4$ & $\begin{array}{c}280.15281 .15282 .15 \\
283.15284 .15\end{array}$ & $\begin{array}{c}\text { Constant at } 2,2.5,3,3.5 \\
\text { and } 4\end{array}$ & $\begin{array}{c}0.617 \mathrm{~mol} \%, 0.756 \mathrm{~mol} \% \text { and } 0.901 \\
\text { mol\% TBAB }\end{array}$ & $\begin{array}{l}\text { Continuous stirred- } \\
\text { tank reactor }\end{array}$ \\
\hline This study & $34.6 / 65.4$ & $\begin{array}{c}280.15281 .15282 .15 \\
283.15\end{array}$ & $\begin{array}{c}\text { Constant at } 1,1.5,2,2.5, \\
3 \text { and } 3.5\end{array}$ & $\begin{array}{c}0.617 \mathrm{~mol} \%, 0.756 \mathrm{~mol} \%, 0.901 \mathrm{~mol} \% \\
\text { and } 1.052 \mathrm{~mol} \% \mathrm{TBAB}\end{array}$ & $\begin{array}{l}\text { Batch (variable } \\
\text { volume) }\end{array}$ \\
\hline
\end{tabular}




\begin{tabular}{cccc}
\hline Gas & $\mathrm{X} / \mathrm{Pa}^{-1}$ & $\mathrm{Y} / \mathrm{K}$ & $\mathrm{Z} / \mathrm{K}$ \\
\hline $\mathrm{N}_{2}$ & $4.2725 \times 10^{15}$ & 4972.37 & 0.64 \\
$\mathrm{CH}_{4}$ & $2.8754 \times 10^{12}$ & 2452.29 & 29.01 \\
\hline
\end{tabular}

2

3

Table 3 Antoine parameters for the calculation of $\mathrm{f}_{\mathrm{T}}^{0}(\mathrm{~T})^{[47,48]}$

\begin{tabular}{cccc}
\hline $\begin{array}{c}\text { Structure of TBAB semi-clathrate } \\
\text { hydrate }\end{array}$ & $\begin{array}{c}\mathrm{A} / 10^{23} \\
(\mathrm{bar})\end{array}$ & $\mathrm{B}(\mathrm{K})$ & $\mathrm{C}(\mathrm{K})$ \\
\hline $\mathrm{A}$ & 6.3491 & -26596 & -111 \\
$\mathrm{~B}$ & 3.2498 & -18620 & 5.43 \\
\hline
\end{tabular}

4

5

Table 4 Values of parameters used for the calculation of $\mathrm{Oi}^{[47,48]}$

\begin{tabular}{ccccccccc}
$\mathrm{s} 1 / 10^{-8}$ & $\mathrm{~s} 2 / 10^{-6}$ & $\mathrm{~s} 3$ & $\mathrm{~g} 1 / 10^{-6}$ & $\mathrm{~g} 2 / 10^{-6}$ & $\mathrm{~g} 3 / 10^{-8}$ & $\mathrm{q} 1 / 10^{-4}$ & $\mathrm{q} 2 / 10^{-4}$ & $\mathrm{q} 3 / 10^{-4}$ \\
\hline-1.707 & 4.570 & 0 & 5.693 & -3.099 & 4.088 & 4.549 & 5.304 & -7.091 \\
\hline
\end{tabular}

6

Table 5 The effect of $k \cdot \Delta t$ on the calculation results

\begin{tabular}{|c|c|c|c|c|c|c|c|}
\hline $\begin{array}{c}\mathrm{k} \cdot \Delta \mathrm{t} \\
(\mathrm{mol} \cdot \mathrm{mol} \\
\left.\text { water }^{-1}\right)\end{array}$ & $\begin{array}{c}\mathrm{XCH} \\
(\mathrm{mol} \%)\end{array}$ & $\begin{array}{c}\text { УсH4 } \\
(\mathrm{mol} \%)\end{array}$ & $\begin{array}{l}\text { GSCHS } \\
(\mathrm{NL} / \mathrm{L})\end{array}$ & teq $/ \Delta \mathrm{t}$ & $\begin{array}{c}\mid \mathrm{X}_{\mathbf{C H} 4, \mathbf{j}^{-}} \\
\left.\mathrm{X}_{\mathrm{CH} 4, \mathrm{j}-1}\right|_{\max } \\
(\mathrm{mol} \%)\end{array}$ & $\begin{array}{c}\mid \mathrm{y}_{\mathbf{C H} 4, \mathbf{j}^{-}} \\
\left.\mathrm{y}_{\mathbf{C H} 4, \mathbf{j}-1}\right|_{\max } \\
(\mathrm{mol} \%)\end{array}$ & $\begin{array}{c}\mid \mathrm{GSCHS}_{\mathrm{j}}-\mathrm{GSCHS}_{\mathrm{j}} \\
\left.\mathbf{1}\right|_{\max }(\mathrm{NL} / \mathrm{L})\end{array}$ \\
\hline 0.10000 & 51.32 & 23.73 & 11.84 & 31 & 1.686 & 3.799 & 4.715 \\
\hline 0.01000 & 50.22 & 24.50 & 11.80 & 168 & 0.158 & 0.325 & 0.471 \\
\hline 0.00100 & 50.14 & 24.57 & 11.79 & 1622 & 0.016 & 0.032 & 0.047 \\
\hline 0.00010 & 50.13 & 24.57 & 11.79 & 14747 & 0.002 & 0.003 & 0.005 \\
\hline 0.00008 & 50.13 & 24.57 & 11.79 & 18248 & 0.001 & 0.003 & 0.004 \\
\hline 0.00004 & 50.13 & 24.57 & 11.79 & 35336 & 0.001 & 0.001 & 0.002 \\
\hline
\end{tabular}


Table 6 The viscosity $\left(v, \mathrm{~mm}^{2} \mathrm{~s}^{-1}\right)$ of the TBAB solution under atmosphere pressure

\begin{tabular}{|c|c|c|c|c|c|c|c|c|c|c|c|}
\hline \multirow{2}{*}{$\mathrm{T}(\mathrm{K})$} & \multicolumn{2}{|c|}{$1.052 \mathrm{~mol} \% \mathrm{TBAB}$} & \multicolumn{2}{|c|}{$0.901 \mathrm{~mol} \% \mathrm{TBAB}$} & \multicolumn{2}{|c|}{$0.617 \mathrm{~mol} \% \mathrm{TBAB}$} & \multicolumn{2}{|c|}{$0.232 \mathrm{~mol} \% \mathrm{TBAB}$} & \multicolumn{3}{|c|}{ Pure water } \\
\hline & $v$ & Uncertainty & $v$ & Uncertainty & $v$ & Uncertainty & $v$ & Uncertainty & $v$ & Uncertainty & Literature $^{[78]}$ \\
\hline 280.15 & 3.069 & 0.006 & 2.759 & 0.003 & 2.335 & 0.003 & 1.694 & 0.003 & 1.428 & 0.005 & 1.428 \\
\hline 283.15 & 2.718 & 0.002 & 2.418 & 0.006 & 1.998 & 0.003 & 1.507 & 0.004 & 1.307 & 0.003 & 1.308 \\
\hline 286.15 & 2.437 & 0.007 & 2.213 & 0.008 & 1.810 & 0.004 & 1.418 & 0.005 & 1.202 & 0.004 & 1.203 \\
\hline 289.15 & 2.176 & 0.002 & 2.013 & 0.006 & 1.684 & 0.006 & 1.305 & 0.006 & 1.107 & 0.004 & 1.111 \\
\hline
\end{tabular}

Table 7 The interfacial tension $\left(\sigma, \mathrm{mN} \cdot \mathrm{m}^{-1}\right)$ between the TBAB solution and CSG under $283.15 \mathrm{~K}$

\begin{tabular}{|c|cc|cc|cc|cc|}
\hline $\mathrm{P}$ & \multicolumn{2}{|c|}{$1.052 \mathrm{~mol} \% \mathrm{TBAB}$} & \multicolumn{2}{|c|}{$0.617 \mathrm{~mol} \% \mathrm{TBAB}$} & \multicolumn{2}{c|}{$0.232 \mathrm{~mol} \% \mathrm{TBAB}$} & \multicolumn{2}{c|}{ Pure water } \\
$(\mathrm{MPa})$ & $\sigma$ & Uncertainty & $\sigma$ & Uncertainty & $\sigma$ & Uncertainty & $\sigma$ & Uncertainty \\
\hline 0.1 & 51.36 & 0.11 & 52.14 & 0.34 & 59.38 & 0.32 & 74.89 & 0.20 \\
0.6 & 49.84 & 0.67 & 51.68 & 0.43 & 58.16 & 0.49 & 73.16 & 0.31 \\
1.1 & 48.61 & 0.56 & 50.73 & 0.54 & 57.12 & 0.37 & 71.05 & 0.32 \\
\hline
\end{tabular}


Table 8 The separation with different TBAB content

\begin{tabular}{|c|c|c|c|c|c|c|c|c|c|c|c|c|c|c|c|}
\hline \multirow{3}{*}{ Number } & \multirow{3}{*}{$\begin{array}{c}\mathrm{CSG} \\
\left(\mathrm{CH}_{4}\right. \\
\mathrm{mol} \%)\end{array}$} & \multirow{3}{*}{$\begin{array}{c}\mathrm{P} \\
\text { (Mpa) }\end{array}$} & \multicolumn{6}{|c|}{ The $\mathrm{CH}_{4}$ content $(\mathrm{mol} \%)$} & \multirow{2}{*}{\multicolumn{3}{|c|}{ GSCHS（NL/L） }} & \multirow{2}{*}{\multicolumn{2}{|c|}{ SF }} & \multirow{2}{*}{\multicolumn{2}{|c|}{$\mathrm{RF}(\%)$}} \\
\hline & & & \multicolumn{3}{|c|}{ The dissociated gas } & \multicolumn{3}{|c|}{ The residual gas } & & & & & & & \\
\hline & & & Exp. & Uncertainty & Cal. & Exp. & Uncertainty & Cal. & Exp. & Uncertainty & Cal. & Exp. & Uncertainty & Exp. & Uncertainty \\
\hline E1 & 34.6 & 2.5 & 50.9 & 0.2 & 50.1 & 23.7 & 0.2 & 24.6 & 12.1 & 0.3 & 11.8 & 3.3 & 0.02 & 59.1 & 1.1 \\
\hline $\mathrm{E} 2$ & 50.9 & 2.5 & 65.8 & 0.4 & 65.1 & 39.3 & 0.2 & 40.0 & 13.1 & 0.3 & 13.1 & 3.0 & 0.03 & 56.6 & 1.2 \\
\hline E3 & 65.9 & 2.5 & 78.3 & 0.2 & 76.6 & 55.5 & 0.2 & 56.5 & 13.7 & 0.3 & 14.1 & 2.9 & 0.01 & 54.3 & 1.3 \\
\hline E4 & 65.9 & 2.0 & 79.4 & 0.3 & 77.5 & 56.8 & 0.3 & 58.1 & 12.0 & 0.3 & 12.1 & 2.9 & 0.07 & 48.4 & 1.0 \\
\hline E5 & 65.9 & 1.5 & 80.1 & 0.1 & 78.4 & 59.8 & 0.2 & 60.2 & 9.0 & 0.3 & 9.5 & 2.7 & 0.03 & 36.4 & 1.0 \\
\hline E6 & 65.9 & 1.0 & 81.3 & 0.1 & 79.6 & 62.4 & 0.1 & 62.8 & 5.6 & 0.1 & 5.6 & 2.6 & 0.01 & 23.0 & 0.5 \\
\hline E7 & 23.7 & 3.5 & 35.7 & 0.2 & 36.8 & 13.3 & 0.1 & 12.7 & 13.9 & 0.2 & 13.7 & 3.6 & 0.02 & 70.0 & 0.5 \\
\hline E8 & 13.3 & 3.5 & 23.2 & 0.1 & 22.9 & 7.2 & 0.1 & 6.4 & 11.4 & 0.1 & 12.5 & 3.9 & 0.04 & 66.6 & 0.7 \\
\hline
\end{tabular}


Table 9 The multistage separation under different operating pressures

\begin{tabular}{|c|c|c|c|c|c|c|c|c|c|c|c|}
\hline \multirow[b]{2}{*}{$\begin{array}{c}\mathrm{S} 1 \\
(\mathrm{MPa})\end{array}$} & \multirow[b]{2}{*}{$\begin{array}{c}\mathrm{S} 22 \\
(\mathrm{MPa})\end{array}$} & \multirow[b]{2}{*}{$\begin{array}{c}\mathrm{S} 32 \\
(\mathrm{MPa})\end{array}$} & \multirow[b]{2}{*}{$\begin{array}{c}\mathrm{S} 21 \\
(\mathrm{MPa})\end{array}$} & \multirow[b]{2}{*}{$\begin{array}{c}\mathrm{S} 31 \\
(\mathrm{MPa})\end{array}$} & \multicolumn{2}{|c|}{ The high $\mathrm{CH}_{4}$ content gas } & \multicolumn{2}{|c|}{ The low $\mathrm{CH}_{4}$ content gas } & \multirow[b]{2}{*}{ Rec } & \multirow[b]{2}{*}{ SF } & \multirow[b]{2}{*}{$\begin{array}{l}\mathrm{RF} \\
(\%)\end{array}$} \\
\hline & & & & & $\begin{array}{c}\text { Volume } \\
\text { (NL) }\end{array}$ & $\begin{array}{c}\mathrm{CH}_{4} \text { content } \\
(\mathrm{mol} \%)\end{array}$ & $\begin{array}{l}\text { Volume } \\
\text { (NL) }\end{array}$ & $\begin{array}{c}\mathrm{CH}_{4} \text { content } \\
(\mathrm{mol} \%)\end{array}$ & & & \\
\hline 3.5 & 3.5 & 3.5 & 3.5 & 3.5 & 4.5 & 71.1 & 5.5 & 4.5 & 2.5 & 52.4 & 92.8 \\
\hline 3.0 & 3.0 & 3.0 & 3.0 & 3.0 & 3.8 & 76.3 & 6.2 & 8.8 & 2.5 & 33.3 & 84.2 \\
\hline 2.5 & 2.5 & 2.5 & 2.5 & 2.5 & 2.9 & 81.0 & 7.1 & 15.7 & 2.4 & 22.9 & 67.8 \\
\hline 3.5 & 2.0 & 2.0 & 3.5 & 3.5 & 3.6 & 82.0 & 6.4 & 7.8 & 3.4 & 53.7 & 85.5 \\
\hline 3.5 & 2.0 & 2.0 & 3.5 & 3.0 & 3.5 & 82.0 & 6.5 & 8.9 & 3.3 & 46.4 & 83.2 \\
\hline 3.5 & 2.0 & 2.0 & 3.0 & 3.5 & 3.5 & 82.4 & 6.5 & 9.4 & 3.2 & 44.9 & 82.1 \\
\hline 3.5 & 2.0 & 2.0 & 3.0 & 3.0 & 3.3 & 82.3 & 6.6 & 10.6 & 3.1 & 39.3 & 79.6 \\
\hline$\underline{3.5}$ & $\underline{3.5}$ & $\underline{1.0}$ & $\underline{3.5}$ & $\underline{3.5}$ & $\underline{3.5}$ & $\underline{84.1}$ & $\underline{6.5}$ & 7.6 & $\underline{3.4}$ & $\underline{64.5}$ & $\underline{85.7}$ \\
\hline 3.5 & 3.0 & 1.0 & 3.5 & 3.5 & 3.4 & 85.3 & 6.6 & 8.6 & 3.6 & 61.7 & 83.4 \\
\hline 3.5 & 2.0 & 1.0 & 3.5 & 3.5 & 3.0 & 88.2 & 7.0 & 12.1 & 4.3 & 54.1 & 75.2 \\
\hline 3.5 & 1.0 & 1.0 & 3.5 & 3.5 & 1.9 & 91.9 & 8.1 & 21.5 & 6.0 & 41.5 & 49.5 \\
\hline 3.5 & 3.5 & 3.0 & 3.5 & 3.5 & 4.4 & 72.3 & 5.6 & 4.6 & 2.5 & 54.5 & 92.6 \\
\hline 3.5 & 3.5 & 2.0 & 3.5 & 3.5 & 4.2 & 76.0 & 5.8 & 5.0 & 2.7 & 60.2 & 91.5 \\
\hline 3.5 & 3.5 & 1.5 & 3.5 & 3.5 & 3.9 & 79.1 & 6.1 & 5.6 & 2.9 & 63.5 & 90.1 \\
\hline 2.5 & 3.5 & 1.0 & 3.5 & 3.5 & 3.1 & 86.3 & 6.9 & 11.6 & 3.4 & 48.2 & 76.8 \\
\hline 2.0 & 3.5 & 1.0 & 3.5 & 3.5 & 2.7 & 87.6 & 7.3 & 14.6 & 3.4 & 41.2 & 69.2 \\
\hline
\end{tabular}


Table 10 The multistage separation under different operating temperatures

\begin{tabular}{|c|c|c|c|c|c|c|c|c|c|c|c|}
\hline \multirow[b]{2}{*}{$\mathrm{S} 1(\mathrm{~K})$} & \multirow[b]{2}{*}{ S22 (K) } & \multirow[b]{2}{*}{ S32 (K) } & \multirow[b]{2}{*}{ S21 $(\mathrm{K})$} & \multirow[b]{2}{*}{ S31 (K) } & \multicolumn{2}{|c|}{ The high $\mathrm{CH}_{4}$ content gas } & \multicolumn{2}{|c|}{ The low $\mathrm{CH}_{4}$ content gas } & \multirow[b]{2}{*}{$\operatorname{Rec}$} & \multirow[b]{2}{*}{ SF } & \multirow[b]{2}{*}{$\mathrm{RF}(\%)$} \\
\hline & & & & & Volume (NL) & $\mathrm{CH}_{4}$ content $(\mathrm{mol} \%)$ & Volume (NL) & $\mathrm{CH}_{4}$ content $(\mathrm{mol} \%)$ & & & \\
\hline 281.15 & 281.15 & 281.15 & 281.15 & 281.15 & 3.5 & 84.1 & 6.5 & 7.6 & 3.4 & 64.5 & 85.7 \\
\hline 280.15 & $\underline{280.15}$ & $\underline{280.15}$ & $\underline{280.15}$ & $\underline{280.15}$ & $\underline{3.9}$ & $\underline{81.0}$ & $\underline{6.1}$ & $\underline{5.5}$ & $\underline{3.4}$ & $\underline{73.0}$ & $\underline{90.1}$ \\
\hline 280.15 & 280.15 & 281.15 & 280.15 & 280.15 & 3.8 & 82.3 & 6.2 & 5.9 & 3.5 & 74.2 & 89.3 \\
\hline 280.15 & 280.15 & 282.15 & 280.15 & 280.15 & 3.5 & 85.5 & 6.5 & 7.6 & 3.9 & 71.1 & 85.5 \\
\hline 281.15 & 280.15 & 280.15 & 280.15 & 280.15 & 3.8 & 81.2 & 6.2 & 5.7 & 3.3 & 71.3 & 89.7 \\
\hline 280.15 & 281.15 & 280.15 & 280.15 & 280.15 & 3.8 & 81.1 & 6.2 & 5.5 & 3.4 & 74.3 & 90.2 \\
\hline 280.15 & 280.15 & 280.15 & 281.15 & 280.15 & 3.8 & 80.7 & 6.2 & 5.7 & 3.2 & 69.0 & 89.7 \\
\hline 280.15 & 280.15 & 280.15 & 280.15 & 281.15 & 3.9 & 80.5 & 6.1 & 5.6 & 3.2 & 69.1 & 90.0 \\
\hline
\end{tabular}


Table 12 The major operating conditions of the multistage separation system with temperature fixed at $280.15 \mathrm{~K}$

\begin{tabular}{|c|c|c|c|c|c|c|c|c|c|c|}
\hline \multirow[b]{2}{*}{ Stage } & \multirow[b]{2}{*}{ Pressure (MPa) } & \multirow[b]{2}{*}{ SF } & \multirow[b]{2}{*}{$\begin{array}{l}\text { Ref } \\
(\%)\end{array}$} & \multirow[b]{2}{*}{$\begin{array}{c}\text { TBAB } \\
\text { solution (L) }\end{array}$} & \multicolumn{3}{|c|}{ Inlet gas } & \multicolumn{3}{|c|}{ Outlet gas } \\
\hline & & & & & From & $\begin{array}{c}\text { Volume } \\
(\mathrm{NL})\end{array}$ & $\begin{array}{c}\mathrm{CH}_{4} \text { content } \\
(\mathrm{mol} \%)\end{array}$ & To & $\begin{array}{c}\text { Volume } \\
(\mathrm{NL})\end{array}$ & $\begin{array}{c}\mathrm{CH}_{4} \text { content } \\
(\mathrm{mol} \%)\end{array}$ \\
\hline \multirow{2}{*}{$\mathrm{S} 1$} & \multirow{2}{*}{3.5} & \multirow{2}{*}{3.5} & \multirow{2}{*}{ - } & \multirow{2}{*}{1.1} & \multirow{2}{*}{ Mixer 1} & \multirow{2}{*}{33.6} & \multirow{2}{*}{38.6} & Mixer 2_1 & 16.0 & 23.9 \\
\hline & & & & & & & & Mixer 2_2 & 17.5 & 52.1 \\
\hline \multirow{2}{*}{ S 2_1 } & \multirow{2}{*}{3.5} & \multirow{2}{*}{4.0} & \multirow{2}{*}{$47.5 \%$} & \multirow{2}{*}{0.7} & \multirow{2}{*}{ Mixer 2_1 } & \multirow{2}{*}{20.8} & \multirow{2}{*}{23.1} & S 3_1 & 10.9 & 12.0 \\
\hline & & & & & & & & Mix 1 & 9.9 & 35.4 \\
\hline \multirow{2}{*}{ S 2_2 } & \multirow{2}{*}{3.5} & \multirow{2}{*}{2.8} & \multirow{2}{*}{$43.4 \%$} & \multirow{2}{*}{1.1} & \multirow{2}{*}{ Mixer 2_2 } & \multirow{2}{*}{31.5} & \multirow{2}{*}{58.0} & Mix 1 & 13.7 & 43.9 \\
\hline & & & & & & & & S 3_2 & 17.9 & 68.7 \\
\hline \multirow{2}{*}{ S 3_1 } & \multirow{2}{*}{3.5} & \multirow{2}{*}{4.4} & $436 \%$ & 04 & S 31 & 100 & 120 & Outlet & 6.1 & 5.5 \\
\hline & & & $45.0 \%$ & 0.4 & (1) & 10.9 & 12.0 & Mix 2_1 & 4.8 & 20.4 \\
\hline S 32 & 10 & 23 & $78.4 \%$ & 0.6 & $\mathrm{~S} 32$ & 17.9 & 687 & Mix 2_2 & 14.0 & 65.4 \\
\hline & & & $10.4 \%$ & 0.0 & S & 17.9 & 00.1 & Outlet & 3.9 & 81.0 \\
\hline & & & & & CSG & 10.0 & 34.6 & & & \\
\hline Mixer 1 & - & - & - & - & S 2_1 & 9.9 & 35.4 & $\mathrm{~S} 1$ & 33.6 & 38.6 \\
\hline & & & & & S 2_2 & 13.7 & 43.9 & & & \\
\hline Mixer 21 & - & - & - & - & S 1 & 16.0 & 23.9 & S 21 & 208 & 231 \\
\hline & - & & & & S 3_1 & 4.8 & 20.4 & $S 2$ & 20.8 & 23.1 \\
\hline Mixer 22 & $\ldots$ & - & - & - & $\mathrm{S} 1$ & 17.5 & 52.1 & S2 2 & 315 & 580 \\
\hline $1011 \lambda=12$ & & - & - & - & S 3_2 & 14.0 & 65.4 & $3 z_{-} 2$ & & 50.0 \\
\hline
\end{tabular}




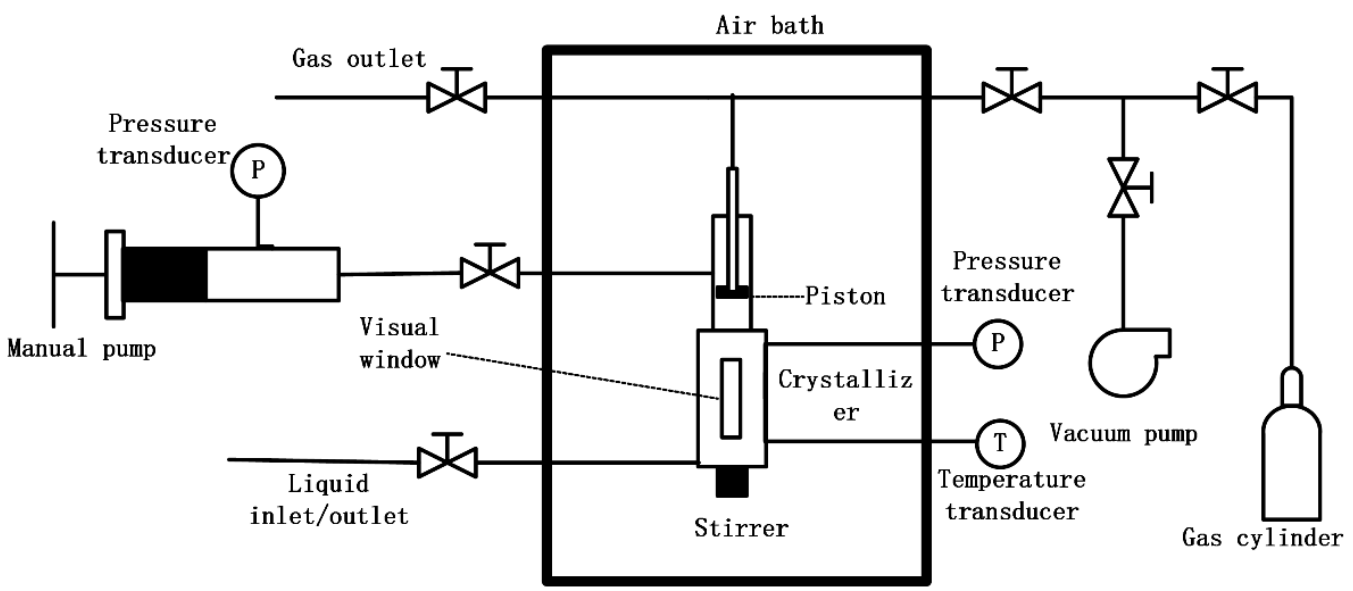

4

Fig. 1. Schematic of experimental apparatus for the hydrate based $\mathrm{CH}_{4}$ separation.

\begin{tabular}{|c|}
\hline Prepared the TBAB solution \\
\hline$\frac{1}{t}$ \\
\hline The crystallizer was washed and dried \\
\hline$\frac{1}{t}$ \\
\hline Adjusted the volume of the crystallizer \\
\hline$\frac{1}{2}+1$ \\
\hline Injected the $\mathrm{TB} A \mathrm{~B}$ solution into the crystallizer \\
\hline$\frac{1}{4}$ \\
\hline $\begin{array}{l}\text { Cooled the crystallizer to the experimental } \\
\text { temperature }\end{array}$ \\
\hline$\frac{1}{4}$ \\
\hline $\begin{array}{l}\text { Removed the gas inside the crystallizer using } \\
\text { CSG and then set to the experimental pressure }\end{array}$ \\
\hline 1 \\
\hline $\begin{array}{c}\text { Isolated the crystallizer and turned on the } \\
\text { stirrer }\end{array}$ \\
\hline$\frac{1}{t}$ \\
\hline $\begin{array}{l}\text { Kept the pressure constant by reducing the } \\
\text { volume of the crystallizer during the hydrate } \\
\text { formation }\end{array}$ \\
\hline$\frac{1}{1}$ \\
\hline $\begin{array}{l}\text { Turned off the stirrer and sampled the residual } \\
\text { gas after the experiment ended }\end{array}$ \\
\hline$\frac{1}{4}+2$ \\
\hline $\begin{array}{c}\text { Removed the gas inside the crystallizer and } \\
\text { warmed the crystallizer to } 298.15 \mathrm{~K} \text { to } \\
\text { dissociate hydrate }\end{array}$ \\
\hline$\frac{1}{1}+1=1$ \\
\hline Sampled the dissociated gas \\
\hline
\end{tabular}

Fig. 2. Schematic of experimental procedure. 


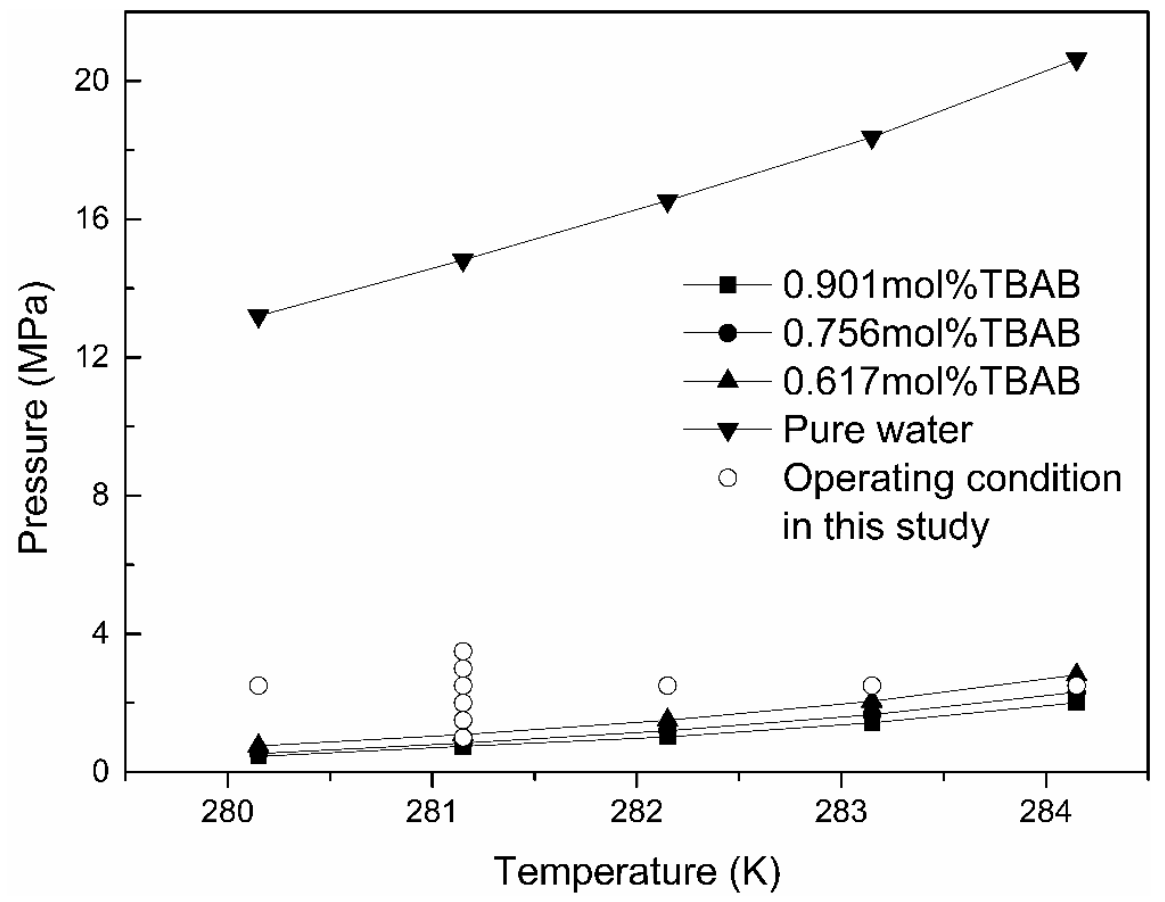

2

Fig. 3. Operating conditions and the equilibrium hydrate formation conditions for the CSG obtained in pure water and in TBAB solutions ${ }^{[13]}$

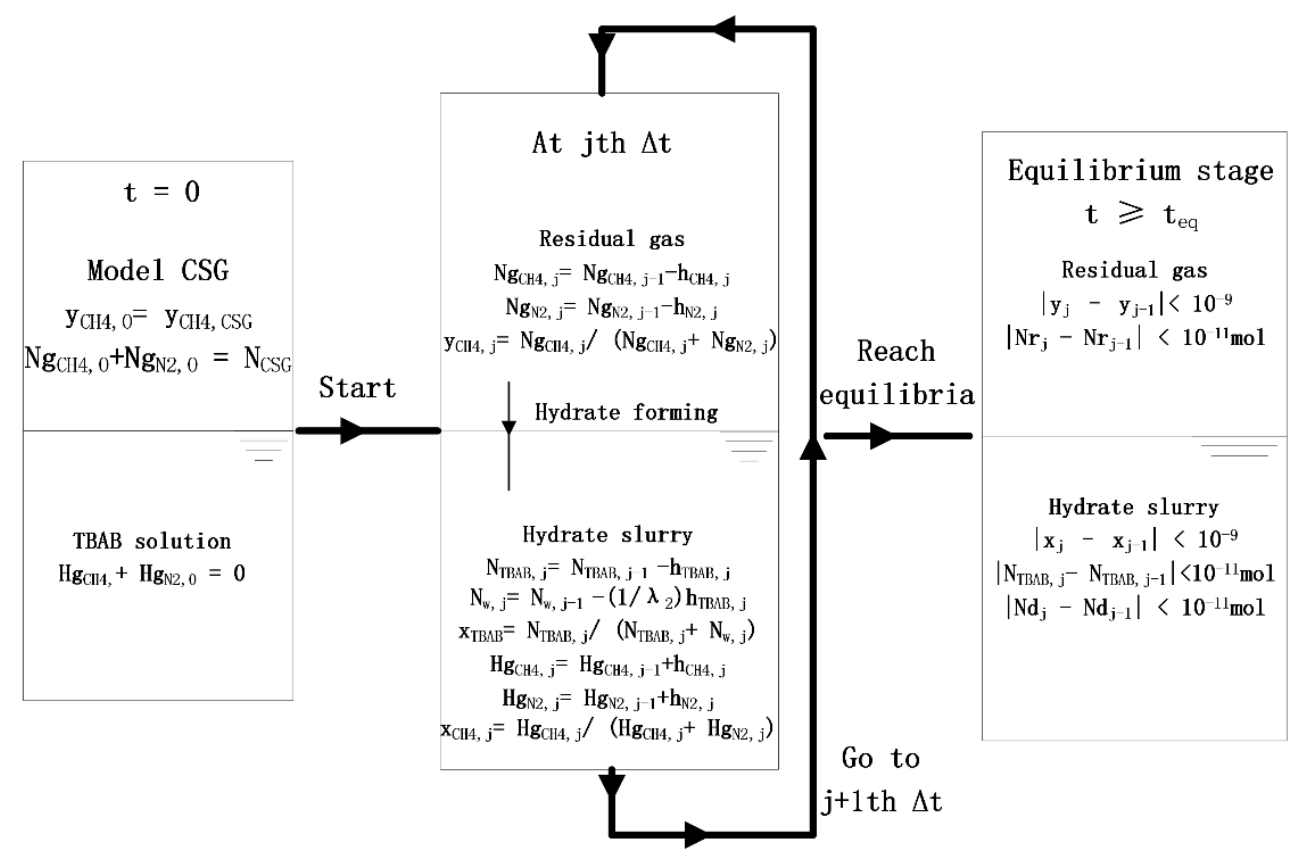

Fig. 4. The conceptual model of the hydrate-based gas separation. 


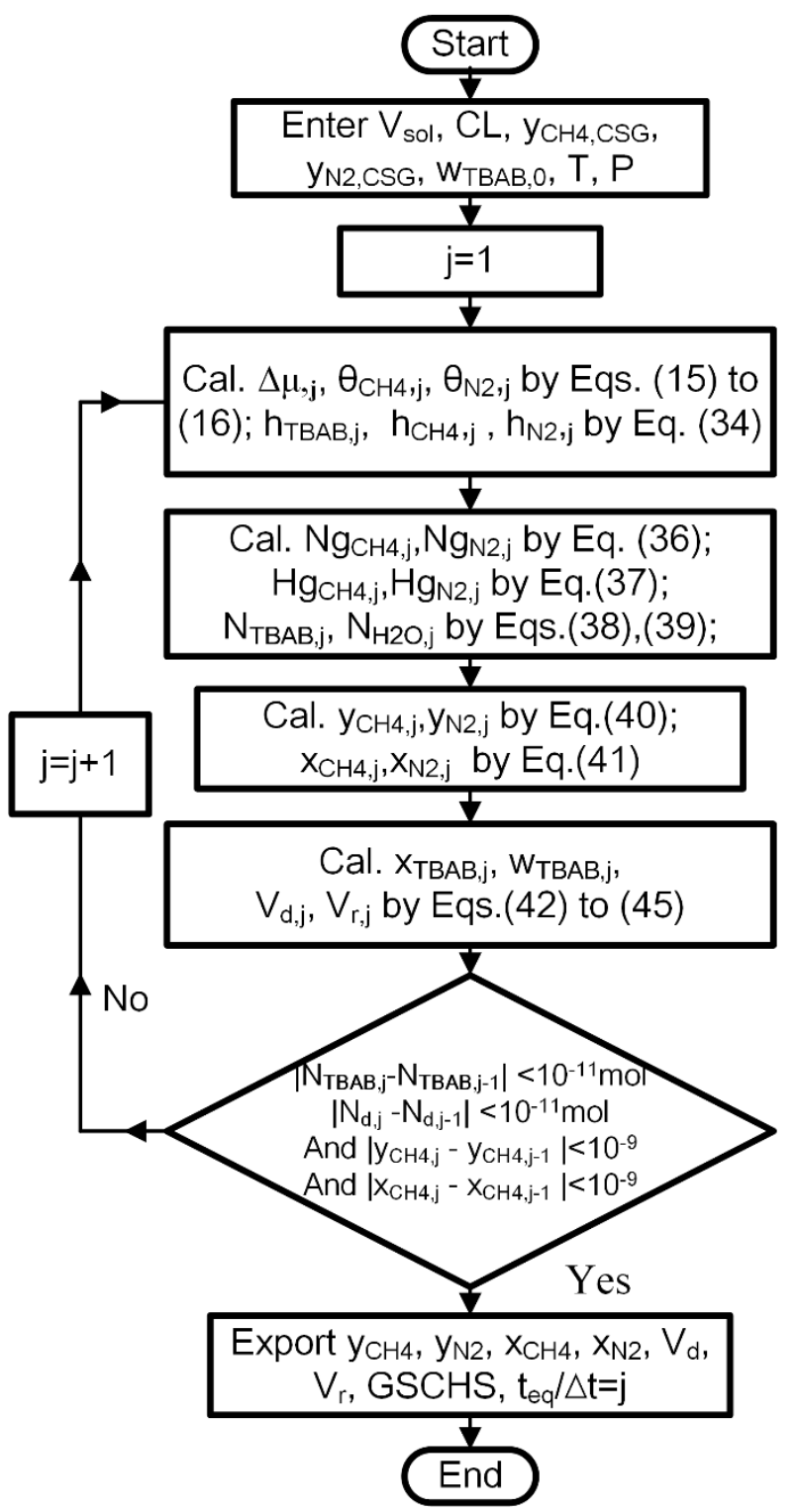

Fig. 5. The procedure of single stage separation calculation. 


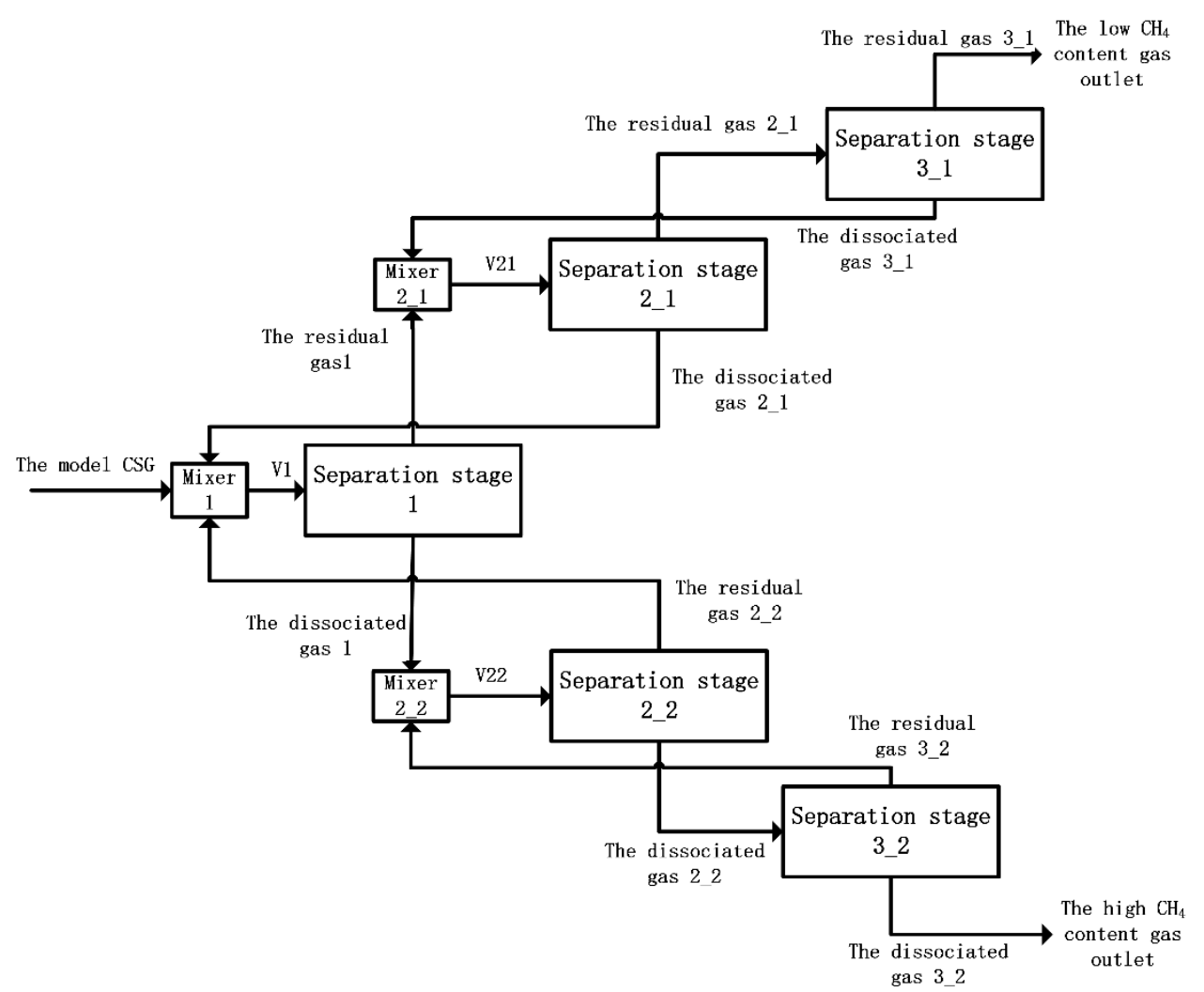

Fig. 6. Schematic diagram of the multistage separation system 


\section{Start}

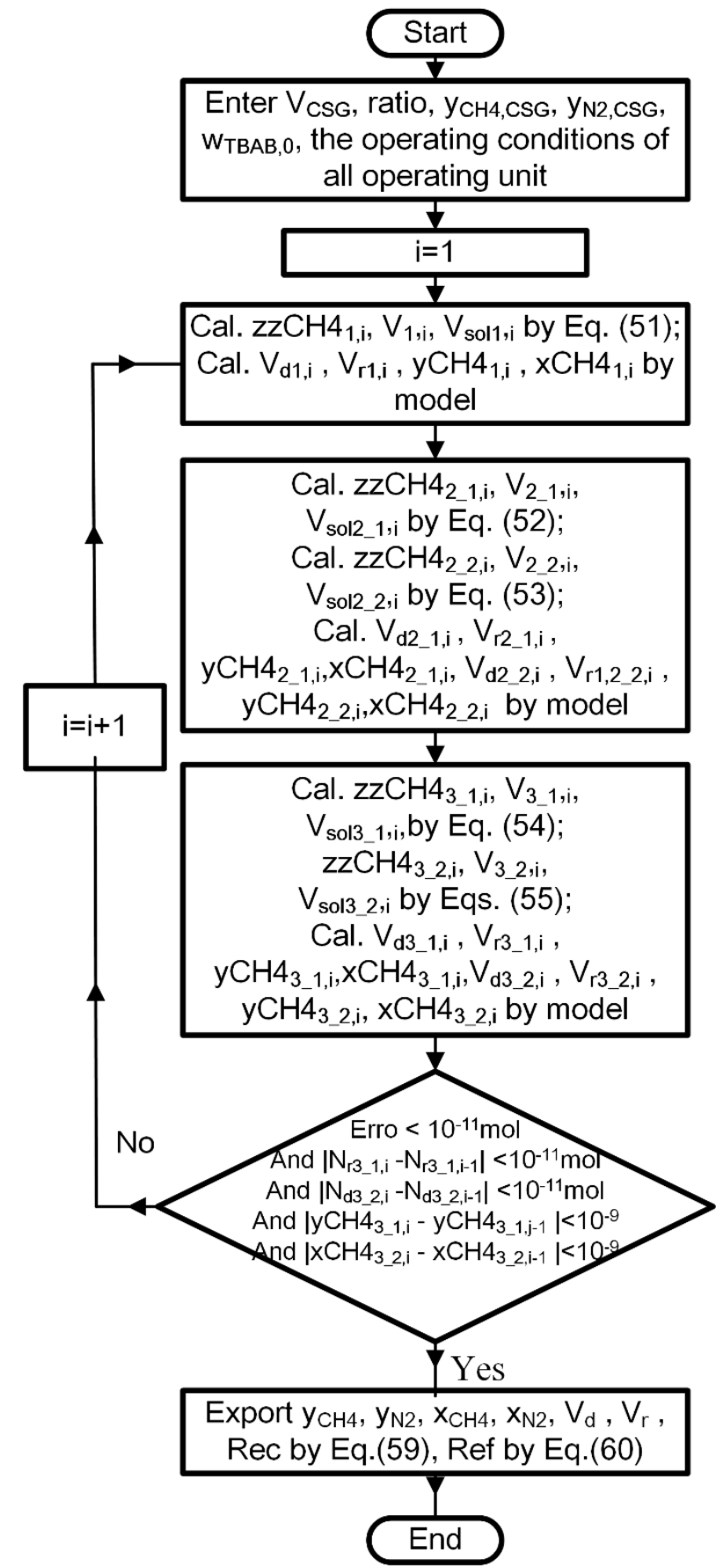

1

2

Fig. 7. The flow chart of the simulation calculation of multistage separation. 


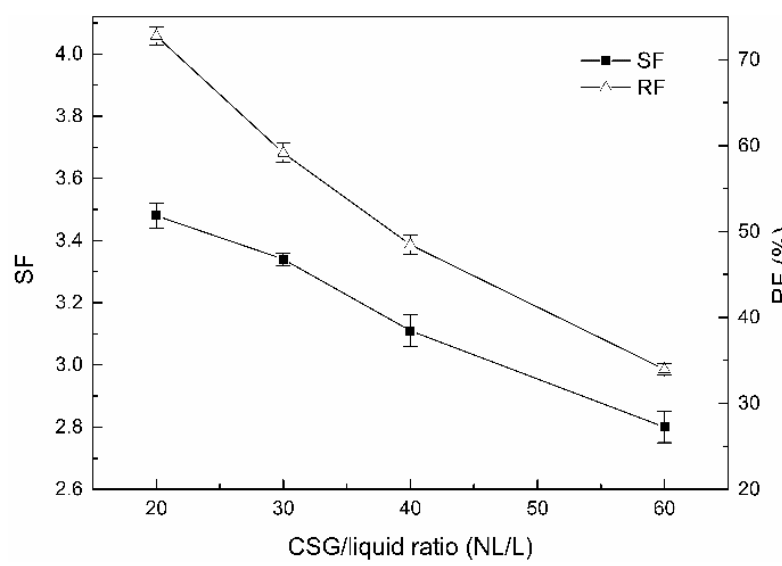

(a)

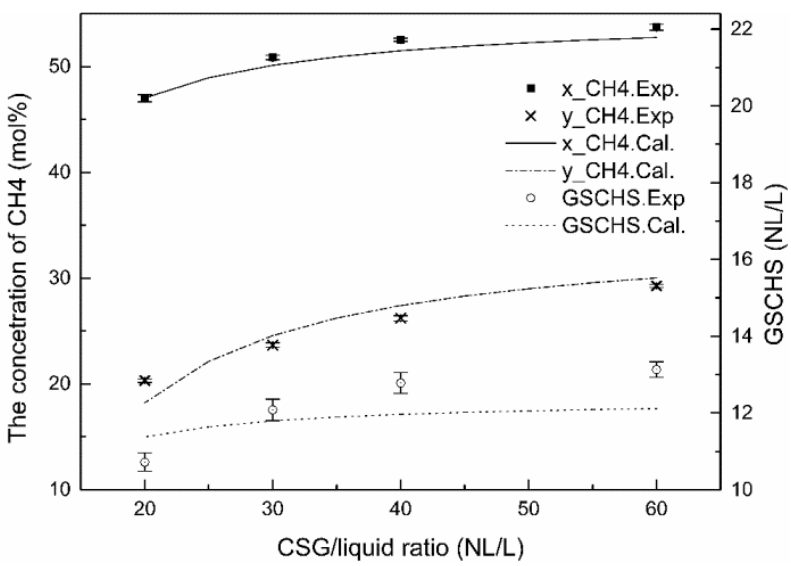

(b)

Fig. 8. Effect of CL on the performance of hydrate based CSG separation. (a) SF and $\mathrm{RF}$; (b) gas compositions and GSCHS.

6

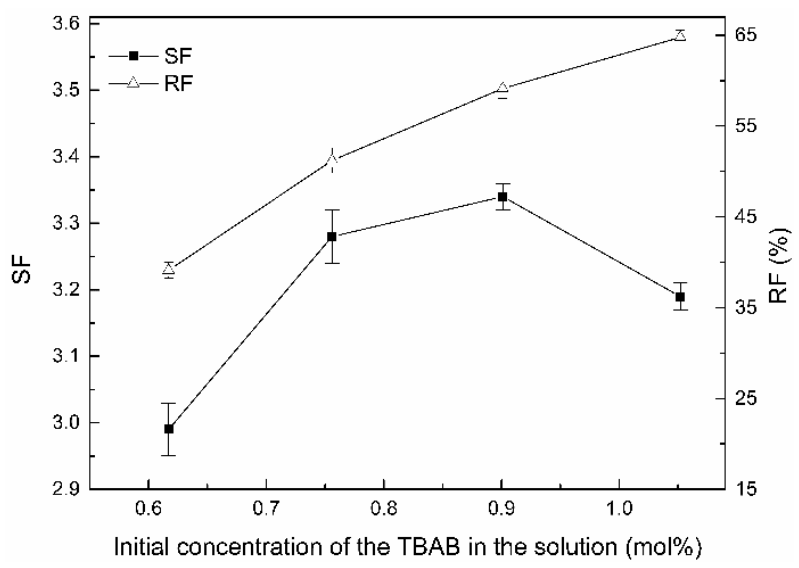

(a)

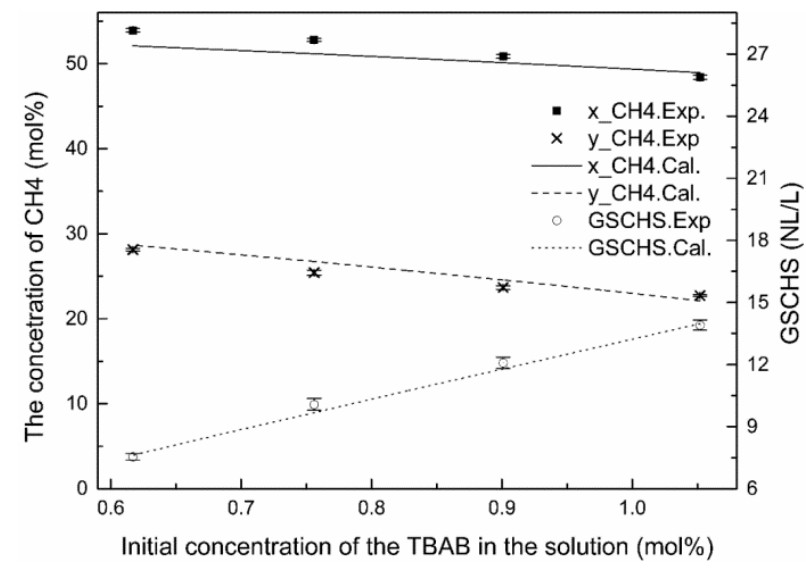

(b)

Fig. 9. Effect of TBAB concentration on the performance of hydrate based CSG separation. (a) SF and RF; (b) gas compositions and GSCHS. 


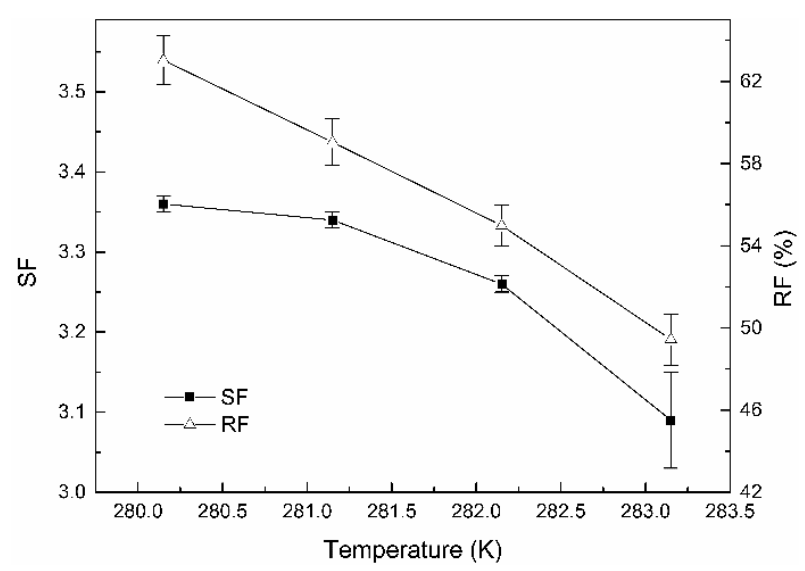

3

4

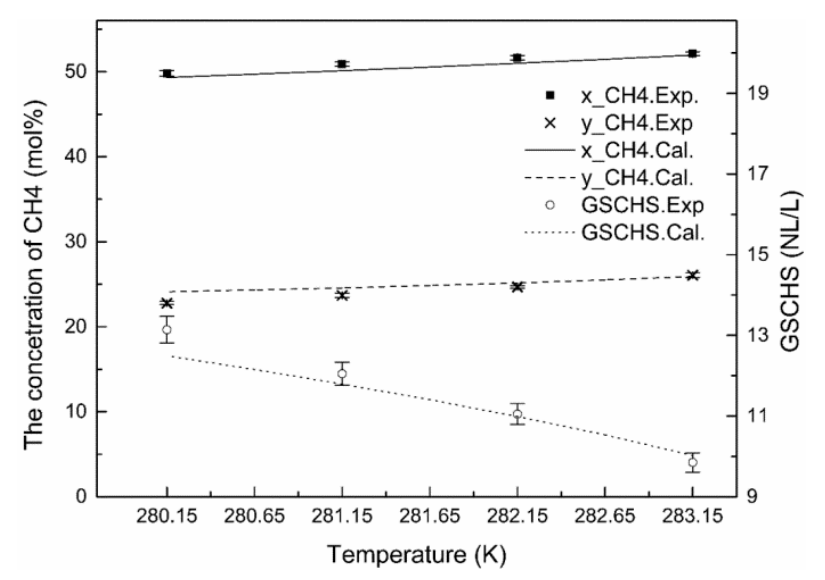

(b)

Fig. 10. Effect of operating temperature on the performance of hydrate based CSG separation. (a) SF and RF; (b) Gas compositions and GSCHS.

6

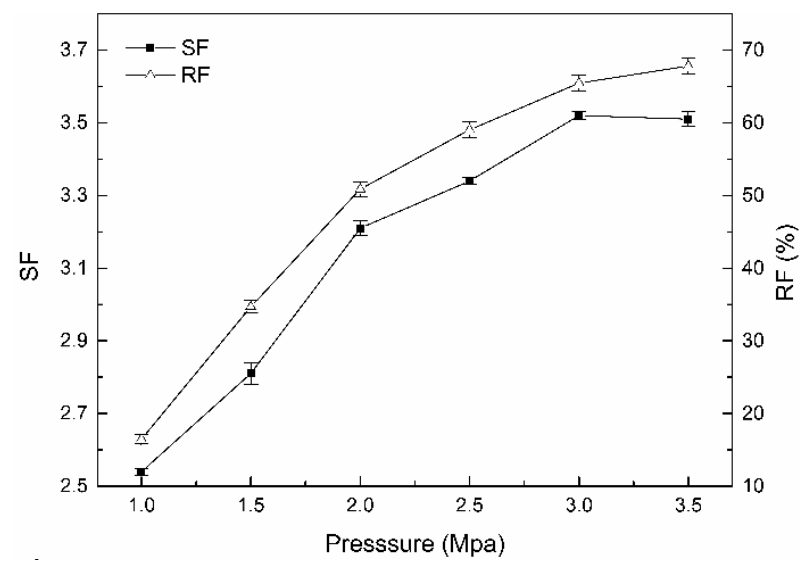

(a)

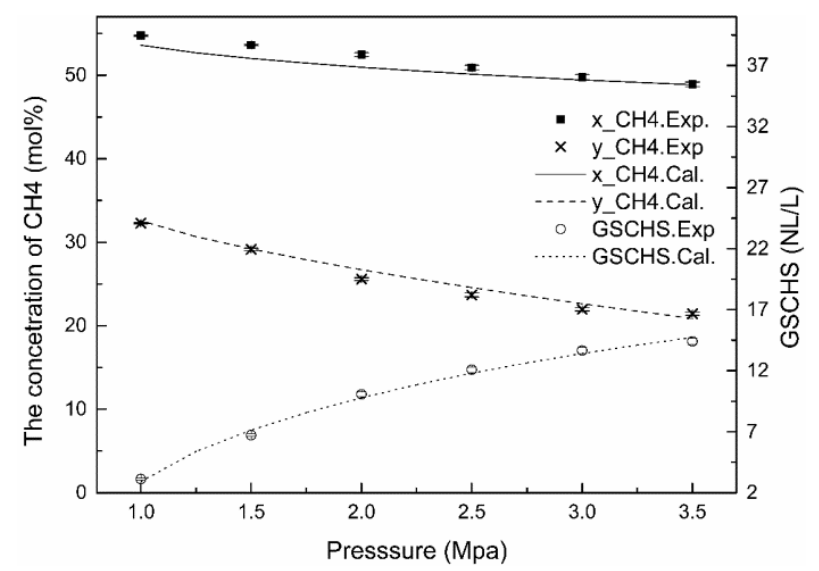

(b)

9 Fig. 11 Effect of operating pressure on the performance of hydrate based CSG 10 separation. (a) SF and RF; (b) Gas compositions and the GSCHS. 